EISSN: $2706-7947$ ISSN: 2077- 4613

DOI: $10.36632 /$ mejas/2021.11.1.12

Journal homepage: www.curresweb.com

Pages: 165-187

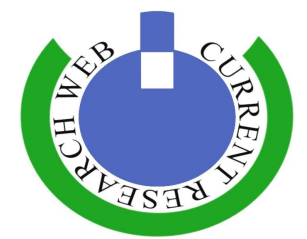

\title{
Susceptibility of Purified Acetylcholinesterases from Rhynchophorus Ferrugineus towards Insecticides and Botanical Extracts
}

\author{
Magda A. Mohamed ${ }^{1}$, Shebl Shaalan², Abd-Elhady M. Ghazy ${ }^{1}$, Atef A. Ali², Ahmed M. \\ Abd-Elaziz ${ }^{1}$, Manal M. Ghanem ${ }^{1}$ and Sarah A. Abd-Elghany ${ }^{1}$ \\ ${ }^{1}$ Molecular Biology Department, National Research Centre, 33-El Buhouth st. Dokki, Giza, Egypt, \\ P.O. 12622 \\ ${ }^{2}$ Zoology Department, Faculty of science, Cairo University, Giza, Egypt, P.O.12316
}

Received: 10 December 2020 Accepted: 15 February $2021 \quad$ Published: 25 February 2021

\begin{abstract}
The susceptibility of two purified acetylcholinesterases (AChEs), AChEIIb and AChEIIIb, from red palm weevil (RPW) Rhynchophorus ferrugineus, to inhibition by different synthetic insecticides and botanical leaves extracts in vitro has been investigated. In addition, the mechanism of inhibition has also been estimated. R. ferrugineus AChEs showed similar trends to inhibition by synthetic insecticides and the inhibition potency can be arranged in a descending order; deltamethrin $>$ carbosufan $>$ oxamyl $>$ emamectin benzoate $>$ chloropyrifose $>$ malathion. All the examined insecticides competitively inhibited $R$. ferrugineus $\mathrm{AChEs}$ with $K i$ values ranging from 0.14 to $0.7 \mathrm{mM}$ and $I C_{50}$ values from 0.15 to $0.75 \mathrm{mM}$, while malathion and emamectin benzoate showed noncompetitive inhibition manner. The susceptibility of $R$. ferrugineus AChEs to inhibition by botanical extracts can be arranged in a descending order: olives Olea europaea $>$ neem Azerachita indica $>$ basil Ocimum basilicum with Ki values ranging from 3.5 to $14 \mathrm{mg}$ and $I C_{50}$ values from 5 to $20 \mathrm{mg}$. $O$. europaea competitively inhibited $R$. ferrugineus AChEs, while the others noncompetitively. By HPLC, oleuropein is the major active compound present in the O. europaea $(96.8 \%)$. Malathion and chloropyrifos, as organophosphate (OP) insecticides, have the least potency to inhibit $R$. ferrugineus AChEs. The susceptibility of $R$. ferrugineus AChEs to insecticides and botanical extracts seems to be a helpful approach for selecting the most efficient insecticide(s) for RPW management. These results may justify the complaint by the farmers regarding the low efficiency of OP insecticides for controlling RPW. O. europaea extract can be examined in vivo for introducing it as integral part of an integrated pest management programs against RPW.
\end{abstract}

Keywords: Acetylcholinesterase, botanical extracts, insecticides, inhibition, red palm weevil.

\section{Introduction}

Red palm weevil (RPW), Rhynchophorus ferrugineus (Olivier) (Coleoptera: Curculionidae) is the major pest serious tissue-boring pest of more than 40 palm species in the Middle East, South and South East Asia, North Africa and Southern Europe (Sharaby and El-Dosary, 2016; Mohamed et al., 2020). The larval stage (grubs) is the most destructive stage and the longest period in the life-cycle of the RPW. The larva remains active for about 1-3 months (Salem, 2015; Salem and Ahmed, 2015). The larvae chew the tender, soft tissues of the palms and moves toward the interior part of the tree (Vatanparast et al., 2014; Sharaby and El-Dosary, 2016; Alzahrani, 2019). The damage caused by the larvae can be seen only long time after infection and finally larval damage results in the death of the infected tree (Sharaby and El-Dosary, 2016; Mahmoud et al., 2017; Alzahrani, 2019).

The management of RPW represents a tremendous challenge because of its cryptic life cycle. Current methods recommended for management of Rhynchophorus species have focused on integrated pest management (IPM) involving surveillance, pheromone lures, cultural control and chemical

Corresponding Author: Manal M. E. Ghanem, Molecular Biology Department, National Research Centre, 33El-Buhouth St., Dokki, Cairo, Egypt P.O.12622. E-mail: d.manalnrc@yahoo.com 
insecticide treatments (Vidyasagar et al., 2000; Salama et al., 2004; Sharaby and El-Dosary, 2016; Salem and Abdel Salam, 2018). The application of synthetic insecticides remains the main strategy for control. However, the development of insect resistance, the high operational cost, the adverse effects of these synthetic chemical insecticides both on human and environmental health and the undesirable side effects have limited the usage of insecticides.

Along the late decades all over the world, so many plant species have been examined for their insecticidal activities as antifeedant, growth retarding, morphogenic, impairing, reproductive disturbing and oviposition deterrenting effects on various insect pests (Senthil-Nathan, 2013; Kolawole et al., 2014; Salem et al.,2016; Salem and Abdel Salam, 2018; Abdel-Aziz, 2019; Oni et al., 2019). The insecticidal effects of various plant extracts against RPW have been proven (Bream et al., 2001; Sharaby and Al-Dosary, 2014; 2016; Abdel Kareim et al., 2017; Salem and Abdel Salam, 2018; Ali et al., 2019). The toxic effects of basil, Osimum basilicum (Abdel Kareim et al., 2017) and neem, Azadirachta indica (Bream et al., 2001; Ali et al., 2019) on different stages of $R$. ferrugineus have been investigated. Although the toxic effects of the botanical insecticides on different insect species have been extensively published, the information about their mode of action is still so scanty. Oni et al (2019) suggested that once the insecticidal potential of a botanical extract has been discovered, its effects on various enzymes of insects should be addressed.

Insects can metabolize and degrade the toxic chemicals for surviving in a chemically unfriendly environment. The ineffectiveness of viable insecticides for management of $R$. phoenicis is due to the defense system inherent to the insect (Bamidele et al., 2013; 2017). The high activity level of acetylcholinesterase enzyme (AChE, EC 3.1.1.7) is one of the main resistance mechanisms in various insecticide-resistant pests (Yu et al., 2006; Pethuan et al., 2007; Yang et al., 2008; Kim et al., 2012; Mohamed et al., 2017). Acetylcholinesterase is a key enzyme catalyzing the hydrolysis of the neurotransmitter, acetylcholine, in the nervous system in various organisms (Zibaee, 2011; SenthilNathan, 2013; Rana et al., 2015; Mohamed et al., 2017). AChE is primarily responsible for termination of cholinergic neurotransmission at synapses in the central nervous system of insects. Its inhibition produces a generalized synaptic collapse that lead to paralysis and insect death (Kim et al., 2010; Rajashekar et al., 2014; Oni et al., 2019). Most insects have two AChE isoenzymes but the mode of action is not well established. It has been reported that AChE2 of Bombyx mori and Apis mellifera is the main catalytic enzyme in synaptic transmission rather than AChE1 (Chen et al., 2009; Kim et al., 2012; Santos et al., 2019).

In a previous report, high AChE level has been recorded in the cuticles of RPW larvae, as the most important organ for protecting the larvae from the detrimental chemicals found in their environment (Mohamed et al., 2020). In addition, two predominant AChE isoenzymes have been purified and characterized. The inhibition of AChE activities in different insect species by a variety of plant extracts has been documented (Breuer et al., 2003; Begum et al., 2010; Ghoneim et al., 2012; Olmedo et al., 2015; Prakash, 2015; Rana et al., 2015; Oni et al., 2019). The study of $R$. ferrugineus AChE enzymes is motivated by the fact that those enzymes are the target site for inhibition by insecticides.

The understanding of the molecular basis of the inhibitory effects of different insecticides and botanical extracts on $R$. ferrugineus AChEs could provide an opportunity for developing RPW management strategy to ensure successful implication of such strategy. To achieve this objective, the present work is designed for evaluating the inhibitory effects and the mechanisms of inhibition of different synthetic chemical insecticides belonging to different classes of insecticides and the ethanolic leaves extracts of three different plant species on two purified $R$. ferrugineus AChEs.

\section{Material and Methods}

\subsection{Chemicals:}

Acetylthiocholine (AcSCh) and 5,5'-dithiobis (2-nitrobenoic acid) (DTNB) were purchased from Sigma Aldrich Chemical Co. Sephacryl S-200 and DEAE-Sepharose for chromatography were obtained from Pharmacia Fine Chemicals (Uppsala, Sweden). All reagents and other general chemicals were of analytical grade. Insecticides, organophosphates (OPs) (chloropyrifos and malathion), carbamates 
(oxamyl, carbosulfan), pyrethroid (deltamethrin) and avermectin (emamectin benzoate) were obtained from Agricultural Ministry, Dokki, Giza, Egypt.

\subsection{Collection and preparation of botanical extracts}

The leaves from trees of olive, Olea europaea; neem, Azadirachta indica and basil, Ocimum basilicum were obtained from the garden of Ministry of Agriculture, Dokki, Giza, Egypt. The leaves were rinsed with distilled water, dried in the shade and crushed to generate a fine powder. The plant powders (1g) for each plant were soaked in $10 \mathrm{ml}$ of $70 \%$ ethanol and maintained for $48 \mathrm{~h}$ at room temperature. The suspension ethanol solution was centrifuged at $10000 \mathrm{Xg}$ for $10 \mathrm{~min}$. The filtrates were evaporated to dryness by rotary evaporator, designated as botanical extract, kept inside air-tight container and stored at $-4^{\circ} \mathrm{C}$ for subsequent use.

\subsection{Insect}

The $11^{\text {th }}$ instar larvae of $R$. ferrugineus were obtained from Central Laboratory for Date Palm Research and Development (CLDPRD), Agricultural Research Centre, Dokki, Giza, Egypt.

\subsection{Preparation of Purified AChEs}

The two AChE isoenzymes; AChEIIb and AChEIIIb, have been previously purified from the crude extract of cuticles of the $11^{\text {th }}$ instar larvae of $R$. ferrugineus that exhibited the highest AChEs level according to Mohamed et al., (2020).

\subsection{Enzyme assay}

The activity of AChE was estimated using AcSChI as a substrate according to Ellman et al. (1961). The reaction mixture contained in $1 \mathrm{ml}: 60 \mathrm{mM}$ Tris- $\mathrm{HCl}$ buffer, $\mathrm{pH} 8.5,1 \mathrm{mM}$ AcSChI, $1 \mathrm{mM}$ DTNB. The reaction mixtures were incubated at $37^{\circ} \mathrm{C}$ for $1 \mathrm{~h}$ and the absorbance was measured at 412 $\mathrm{nm}$. One unit of AChE activity was defined as the amount of enzyme that catalyzes the hydrolysis $1 \mu \mathrm{mol}$ of substrate per hour under standard assay conditions.

\subsection{Susceptibility of AChEs to insecticides in vitro}

The susceptibility of purified AChEIIb and AChEIIIb to inhibition by different classes of insecticides was performed. The classes of insecticides included organophosphates (OPs) (chloropyrifos and malathion), carbamates (oxamyl, carbosulfan), pyrethroid (deltamethrin) and avermectin (emamectin benzoate). The enzymes were pre-incubated with 6 different concentrations of each insecticide individually for $15 \mathrm{~min}$ at $25^{\circ} \mathrm{C}$ before substrate, $\mathrm{AcSChI}$, addition for estimating the residual enzyme activities as described previously. Malathion, deltamethrin and oxamyl were used in the concentration ranges $0.25-2.0,0.1-0.4$ and $0.1-0.1 \mathrm{mM}$, respectively. Deltamethrin, carbosulfan and emamectin benzoate were used in the concentration ranges $0.1-0.4,0.1-0.8$ and $0.1-0.6 \mathrm{mM}$, respectively. The median inhibition concentration $\left(\mathrm{IC}_{50}\right)$, the concentration of insecticide that inhibited $50 \%$ of $R$. ferrugineus AChEs activities was determined based on the log-concentration versus $\log (\%$ residual activity) according to Devonshire and Moores (1982). The bimolecular rate constant (Ki) for each insecticide was estimated by the double reciprocal plots of initial velocities versus reciprocal concentrations of AcSChI in the absence and presence of 3 different insecticide concentrations according to Dixon and Webb (1964). The $K i$ values were calculated from the replot of S/V against insecticide concentrations. The mechanism of AChEs inhibition by an insecticide, competitive or noncompetitive was determined according to Dixon and Webb (1964).

\subsection{Susceptibility of AChEs to botanical extracts in vitro}

The susceptibility of purified AChEIIb and AChEIIIb to inhibition by different botanical extracts; $O$. europaea, $A$. indica and $O$. basilicum were examined. The enzymes were pre-incubated with 6 different concentrations of each botanical extract individually for $15 \mathrm{~min}$ at $25^{\circ} \mathrm{C}$ before substrate, AcSChI, addition for estimating the residual enzyme activities as described previously. O. europaea, $A$. indica and $O$. basilicum were used in the concentration ranges 1-10, 2-16 and 2-30 $\mathrm{mg}$, respectively. $\mathrm{IC}_{50}$ and $K i$ for each botanical extract were estimated as mentioned before. 


\subsection{Evaluation of the active compounds present in $O$. europaea}

The high performance liquid chromatography (HPLC) analysis was carried out for $70 \%$ ethanol leaves extract of O. europaea using an Agilent Technologies 1100 series liquid chromatograph equipped with an auto sampler and a diode-array detector. The analytical column was eclipse XDB- C18 (150 x 4.6 $\mu \mathrm{m} ; 5 \mu \mathrm{m}$ ) fitted with $4.0 \times 3.0 \mathrm{~mm}$ i.d. guard column. The mobile phase consisted of acetonitrile (solvent A) and $2 \%$ acetic acid in water (v/v) (solvent B). The flow rate was $1.0 \mathrm{ml} / \mathrm{min}$ for a total run time of 70 min and the gradient program was as follows: $100-85 \% \mathrm{~B}$ in $30 \mathrm{~min}, 85-50 \% \mathrm{~B}$ in $20 \mathrm{~min}, 50-0 \% \mathrm{~B}$ in $5 \mathrm{~min}$ and $0-100 \% \mathrm{~B}$ in $5 \mathrm{~min}$. There was $10 \mathrm{~min}$ of post-run for reconditioning. Peaks were monitored simultaneously at 280, 320 and $360 \mathrm{~nm}$ (Kim et al., 2006). All samples were filtered through a $0.45 \mu \mathrm{m}$ Acrodisc syringe filter (Gelman Laboratory, MI) before injection. Peaks were identified by congruent retention times and UV spectra and compared with those of the standards.

\section{Results}

\subsection{Susceptibility of AChEs to insecticides}

The susceptibility of two purified R. ferrugineus AChEs, AChEIIb and AChEIIIb, to inhibition by six different insecticides were investigated using AcSChI as a substrate. The inhibition kinetic parameters, $\mathrm{IC}_{50}$ and $\mathrm{Ki}$, and the mechanisms of inhibition are presented in Table (1).

Table 1: The inhibition parameters, $\mathrm{IC}_{50}, K i$ values and mechanisms of inhibition, by various insecticides for $R$. ferrugineus and different insect species AChEs in vitro

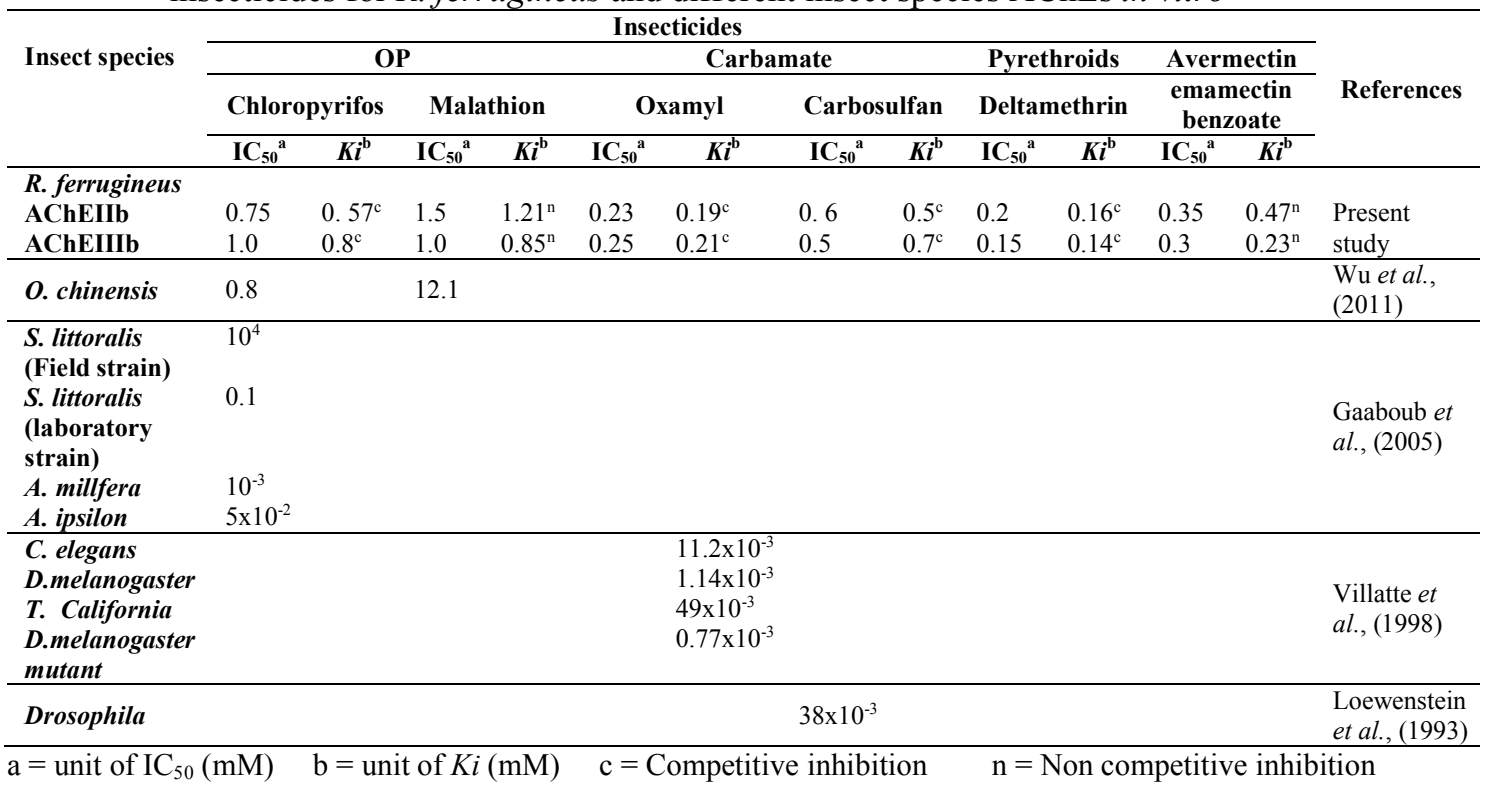

\subsubsection{Susceptibility towards chloropyrifos}

The effect of different chloropyrifos concentrations (Fig. 1) on the activities of $R$. ferrugineus AChEs revealed that a gradual decrease in AChEIIb and AChEIIIb activities with increasing chloropyrifos concentrations and incubation time was observed. Upon incubation of each with $2 \mathrm{mM}$ for $15 \mathrm{~min}, 94 \%$ and $87.3 \%$ of the enzyme activities were suppressed, respectively with $\mathrm{IC}_{50}$ values 0.75 and $1.0 \mathrm{mM}$ for AChEIIb and AChEIIIb, respectively. Chloropyrifos competitively inhibited $R$. ferrugineus AChEIIb and AChEIIIb with Ki values 0.57 and $0.8 \mathrm{mM}$ respectively (Fig. $2 \mathrm{a}, \mathrm{b}$ ). 


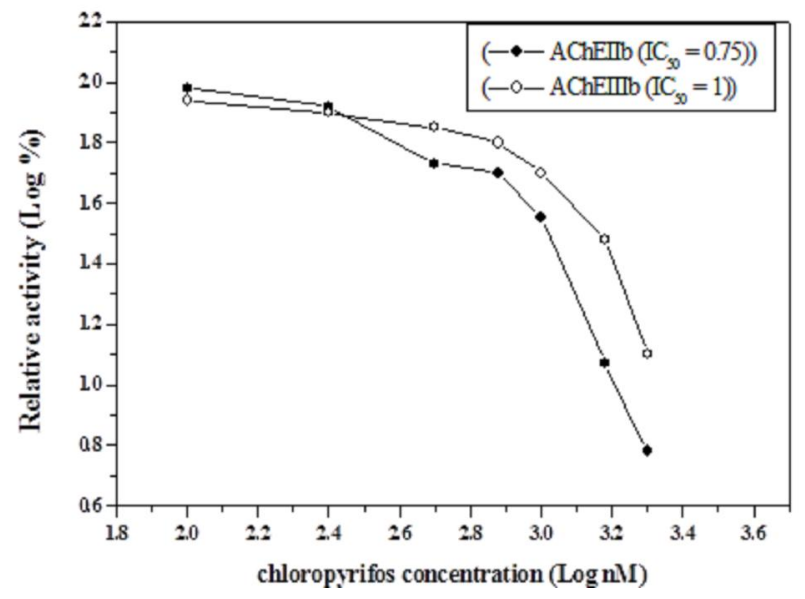

Fig. 1: Effect of different chloropyrifos concentrations on the activities of $R$. ferrugineus AChEs. Purified AChEIIb and AChEIIIb were incubated for 15 min with different concentrations ranging from $0.1-2.0 \mathrm{mM}$ at room temperature followed by estimating the residual activities

(a)

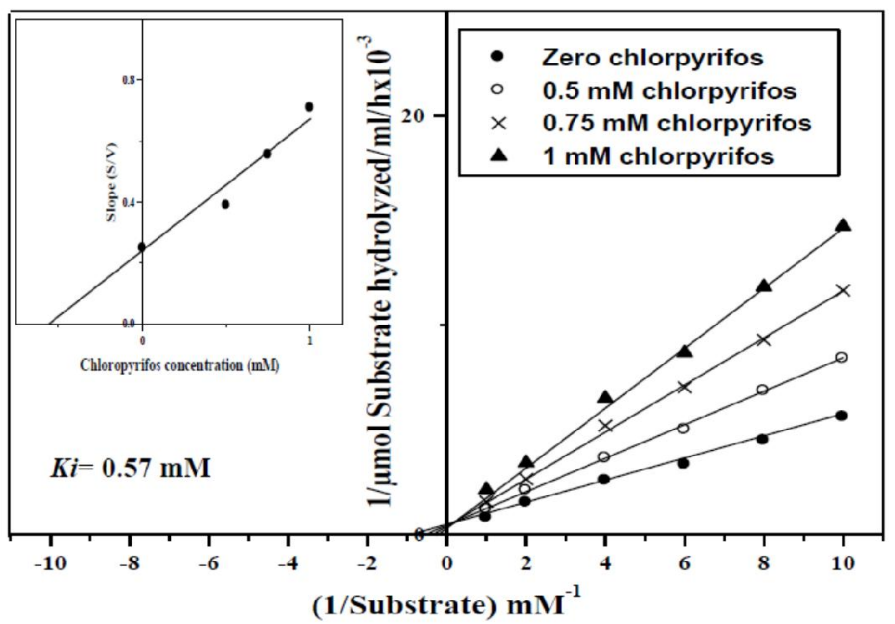

(b)

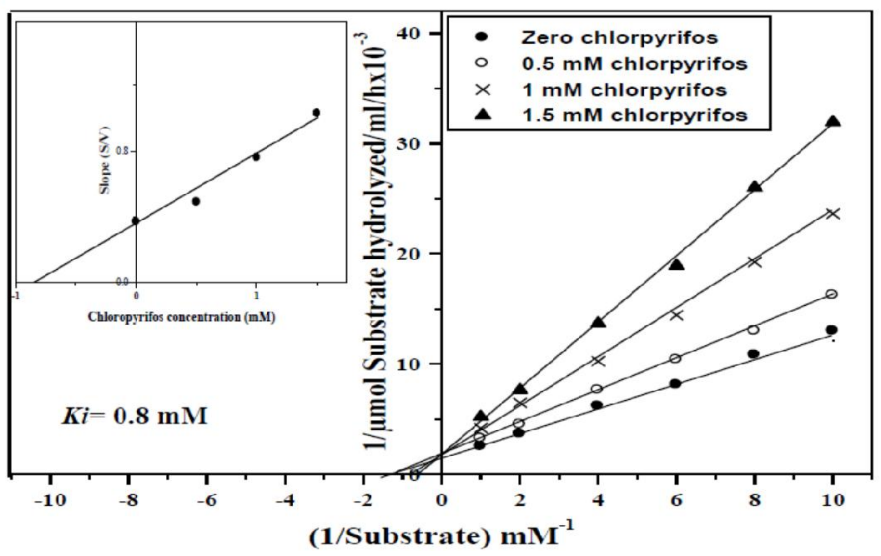

Fig. 2: Reciprocal of initial velocities of (a) AChEIIb and (b) AChEIIIb versus reciprocal concentrations of AcSChI in presence of different concentrations of chloropyrifos. Inhibition constant $(\mathrm{Ki})$ of chloropyrifos was shown in the inset. 


\subsubsection{Susceptibility towards malathion}

A decrease in $R$. ferrugineus AChEIIb and AChEIIIb activities was recorded with increasing malathion concentrations (Fig. 3), where $67 \%$ and $84 \%$ of the activities, respectively were inhibited upon incubation of each with $2.0 \mathrm{mM}$ for $15 \mathrm{~min}$. The $\mathrm{IC}_{50}$ values were 1.5 and $1.0 \mathrm{mM}$ for $\mathrm{AChEIIb}$ and AChEIIIb, respectively. Malathion non-competitively inhibited $R$. ferrugineus AChEIIb and AChEIIIb with $K i$ values 1.2 and 0.85 mM, respectively (Figs. 4 a, b).

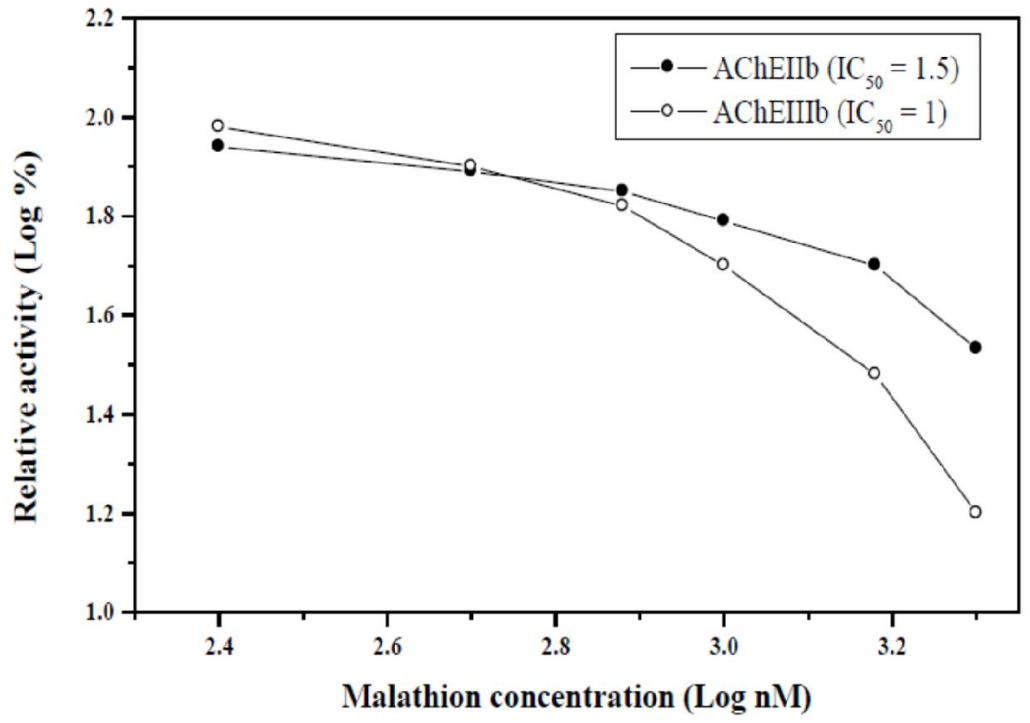

Fig. 3: Effect of different malathion concentrations on the activities of $R$. ferrugineus AChEs. Purified AChEIIb and AChEIIIb were incubated for 15 min with different malathion concentrations ranging from $0.25-2.0 \mathrm{mM}$ at room temperature followed by estimating the residual activities.

\subsubsection{Susceptibility towards oxamyl}

The enzymatic activities of $R$. ferrugineus AChEIIb and AChEIIIb were reduced with increasing oxamyl concentrations (Fig. 5). Upon incubation of each with $0.8 \mathrm{mM}$ for $15 \mathrm{~min}, 92.5 \%$ and $93 \%$ of the activities were inhibited, respectively. The $\mathrm{IC}_{50}$ values were 0.23 and $0.25 \mathrm{mM}$, respectively. Oxamyl competitively inhibited $R$. ferrugineus AChEIIb and AChEIIIb with $K i$ values 0.19 and $0.21 \mathrm{mM}$, respectively (Figs. $6 \mathrm{a}, \mathrm{b}$ ).

\subsubsection{Susceptibility towards carbosulfan}

R. ferrugineus AChEIIb and AChEIIIb enzyme activities were inhibited with increasing carbosulfan concentrations (Fig. 7). Upon incubation of each with $0.8 \mathrm{mM}$ for $15 \mathrm{~min}, 61 \%$ and $73 \%$ of the activities were lost. The $\mathrm{IC}_{50}$ values are 0.6 and $0.5 \mathrm{mM}$, respectively. Carbosulfan competitively inhibited $R$. ferrugineus AChEIIb and AChEIIIb with $K i$ values 0.5 and $0.7 \mathrm{mM}$, respectively (Figs. 8 $\mathrm{a}, \mathrm{b})$.

\subsubsection{Susceptibility towards deltamethrin}

The activities of $R$. ferrugineus AChEIIb and AChEIIIb were suppressed with increasing deltamethrin concentration (Fig. 9). Upon incubation of each with $0.4 \mathrm{mM}$ for $15 \mathrm{~min}, 80 \%$ and $91.3 \%$ of activities were suppressed with $\mathrm{IC}_{50}$ values 0.2 and $0.15 \mathrm{mM}$, respectively. Deltamethrin competitively inhibited $R$. ferrugineus AChEIIb and AChEIIIb with $K i$ values 0.16 and $0.14 \mathrm{mM}$, respectively (Fig. $10 \mathrm{a}, \mathrm{b})$. 
(a)

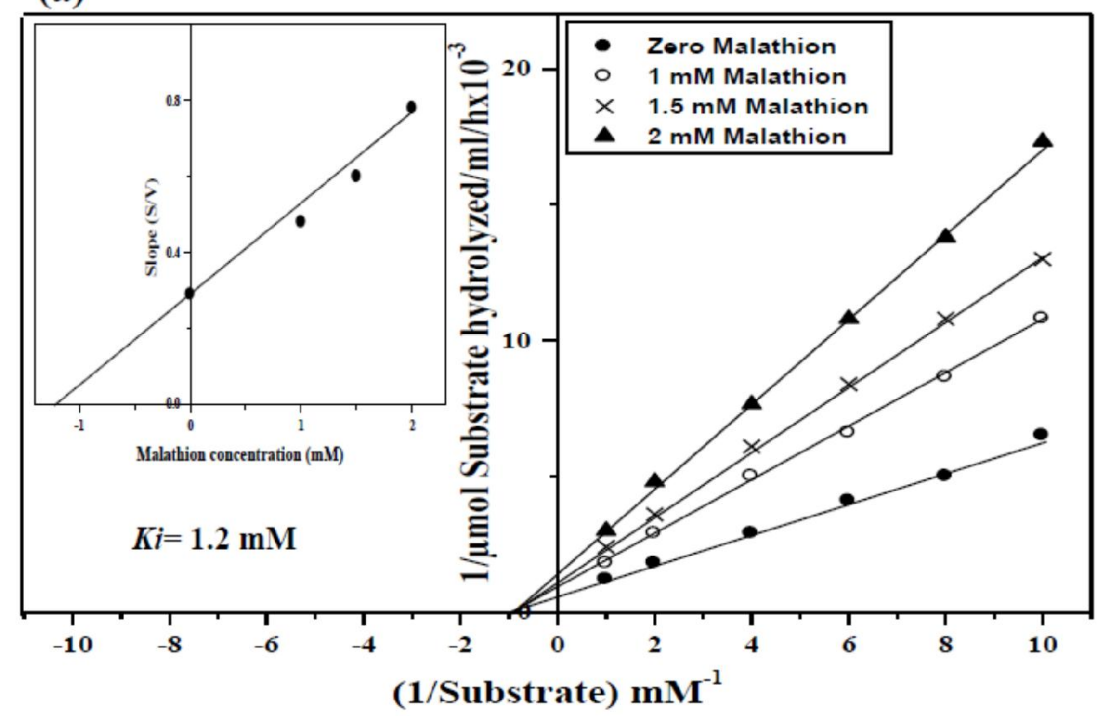

(b)

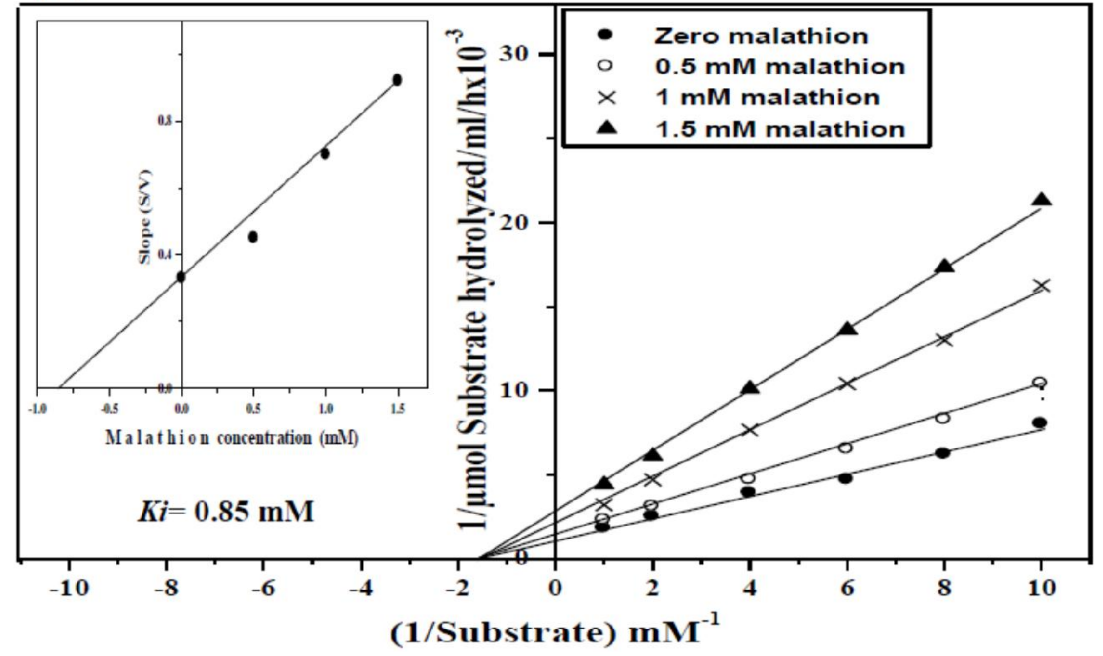

Fig. 4: Reciprocal of initial velocities of (a) AChEIIb and (b) AChEIIIb versus reciprocal concentrations of AcSChI in presence of different concentrations of malathion. $K i$ of malathion was shown in the inset.

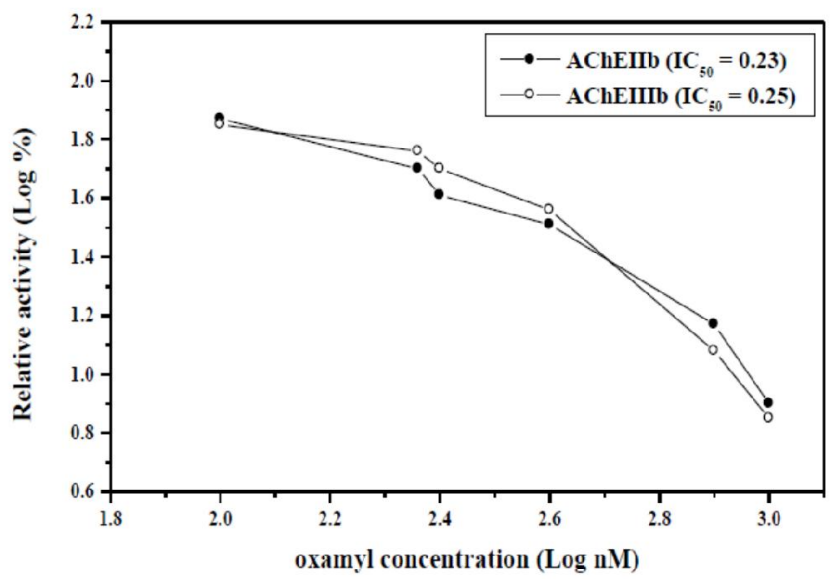

Fig. 5: Effect of different oxamyl concentrations on the activities of $R$. ferrugineus AChEs. Purified AChEIIb and AChEIIIb were incubated for $15 \mathrm{~min}$ with different oxamyl concentrations ranging from $0.1-1.0 \mathrm{mM}$ at room temperature followed by estimating the residual activities. 
(a)

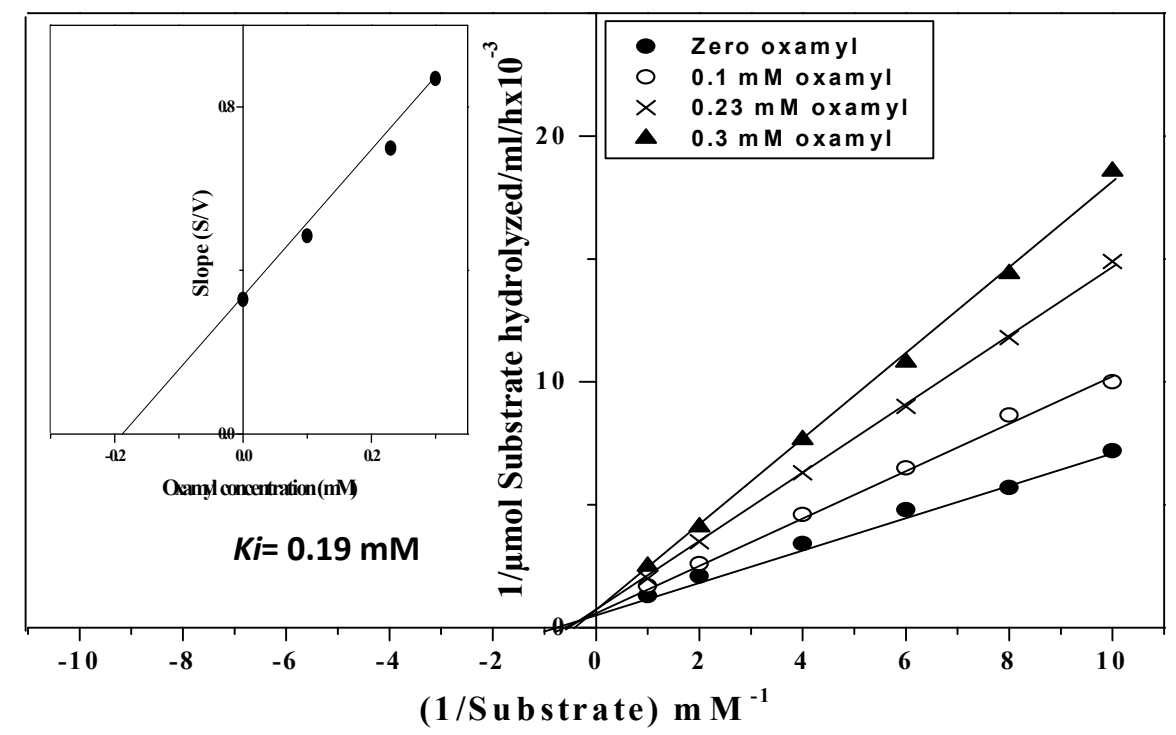

(b)

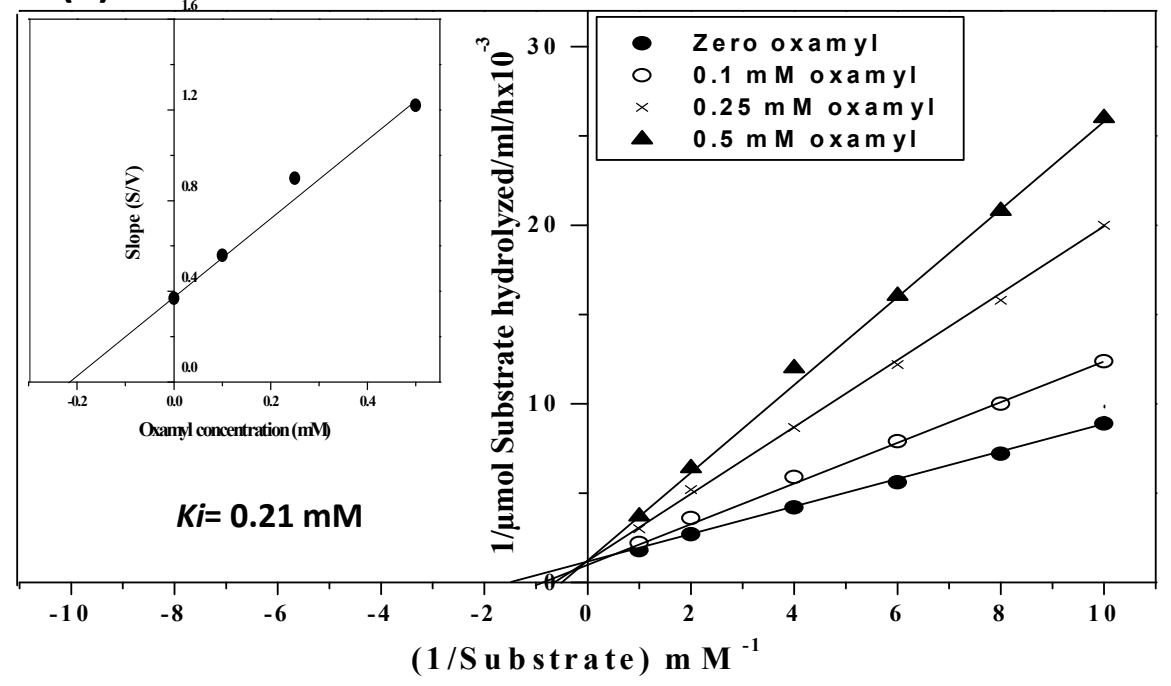

Fig. 6: Reciprocal of initial velocities of (a) AChEIIb and (b) AChEIIIb versus reciprocal concentrations of $\mathrm{AcSChI}$ in presence of different concentrations of oxamyl. Inhibition constant $(\mathrm{Ki})$ of oxamyl was shown in the inset. 


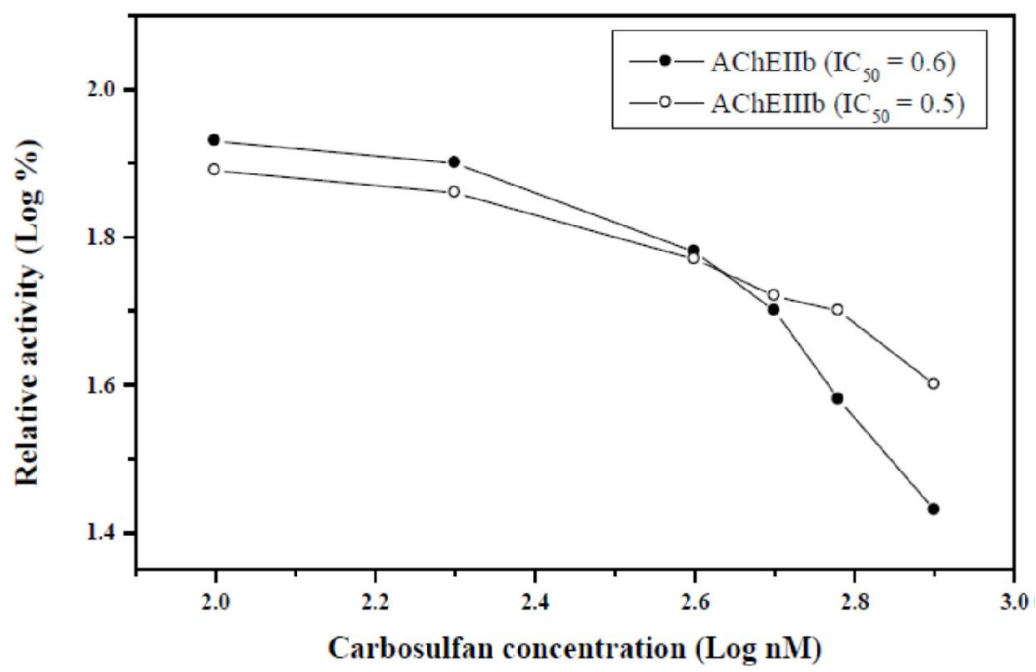

Fig. 7: Effect of different carbosulfan concentrations on the activities of $R$. ferrugineus AChEs. Purified AChEIIb and AChEIIIb were incubated for 15 min with different carbosulfan concentrations ranging from $0.1-0.8 \mathrm{mM}$ at room temperature followed by estimating the residual activities.

\section{(a)}

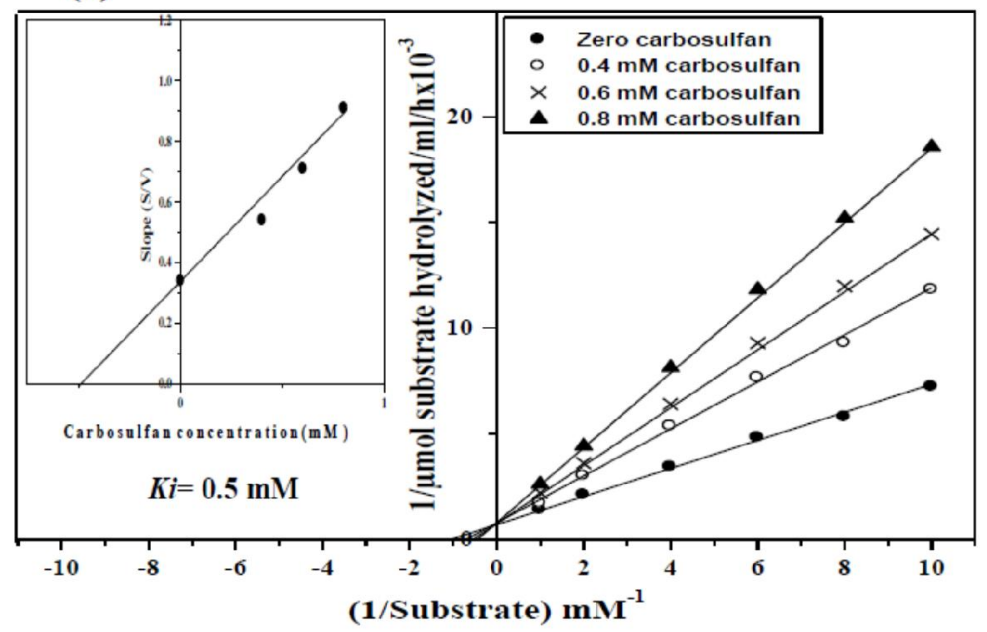

(b)

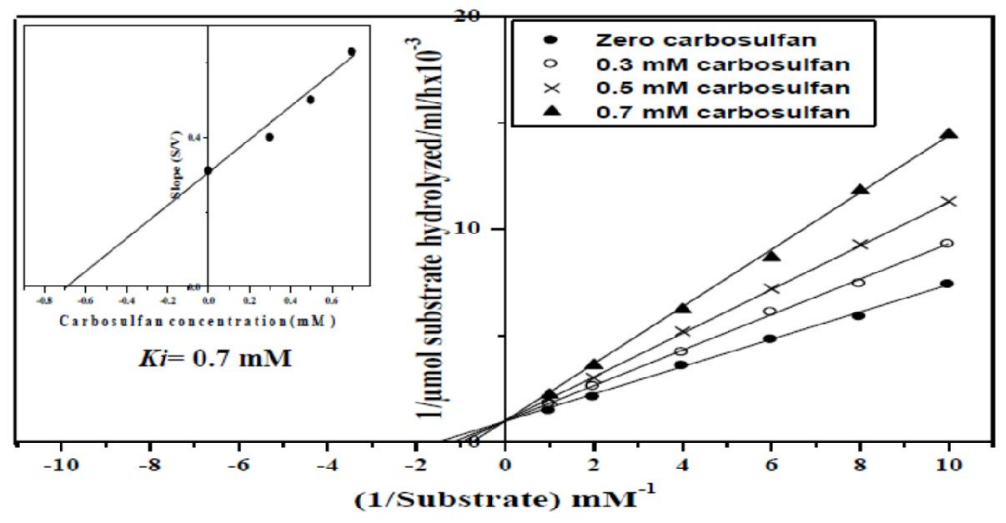

Fig. 8: Reciprocal of initial velocities of (a) AChEIIb and (b) AChEIIIb versus reciprocal concentrations of AcSChI in presence of different concentrations of carbosulfan. Ki of carbosulfan was shown in the inset. 


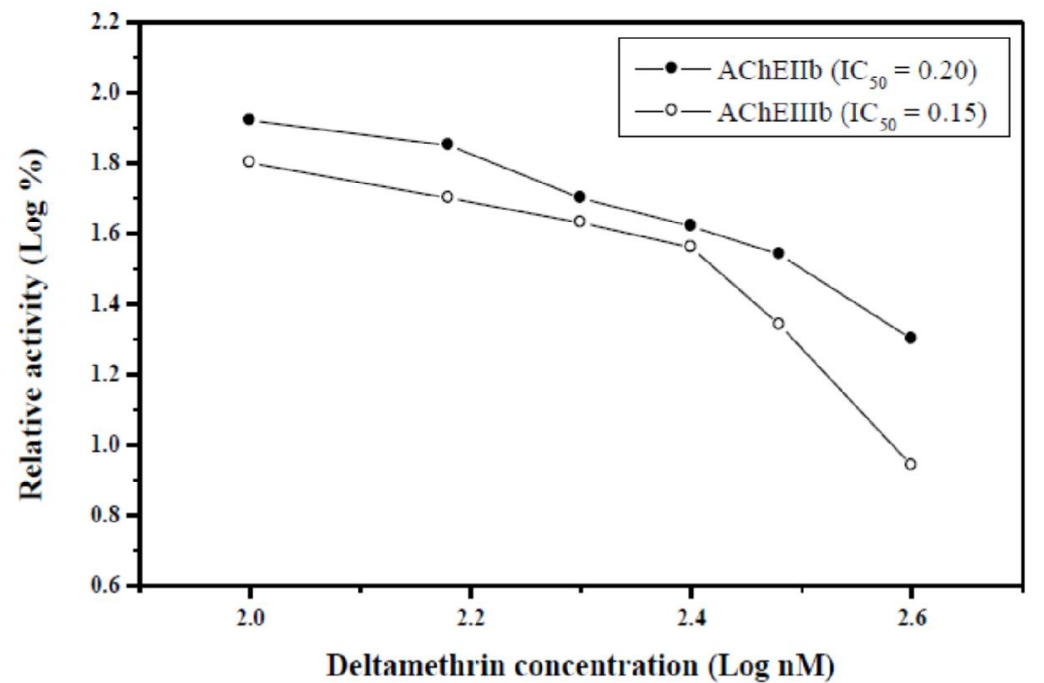

Fig. 9: Effect of different deltamethrin concentrations on the activities of $R$. ferrugineus AChEs. Purified AChEIIb and AChEIIIb were incubated for $15 \mathrm{~min}$ with different deltamethrin concentrations ranging from $0.1-0.4 \mathrm{mM}$ at room temperature followed by estimating the residual activities.

(a)

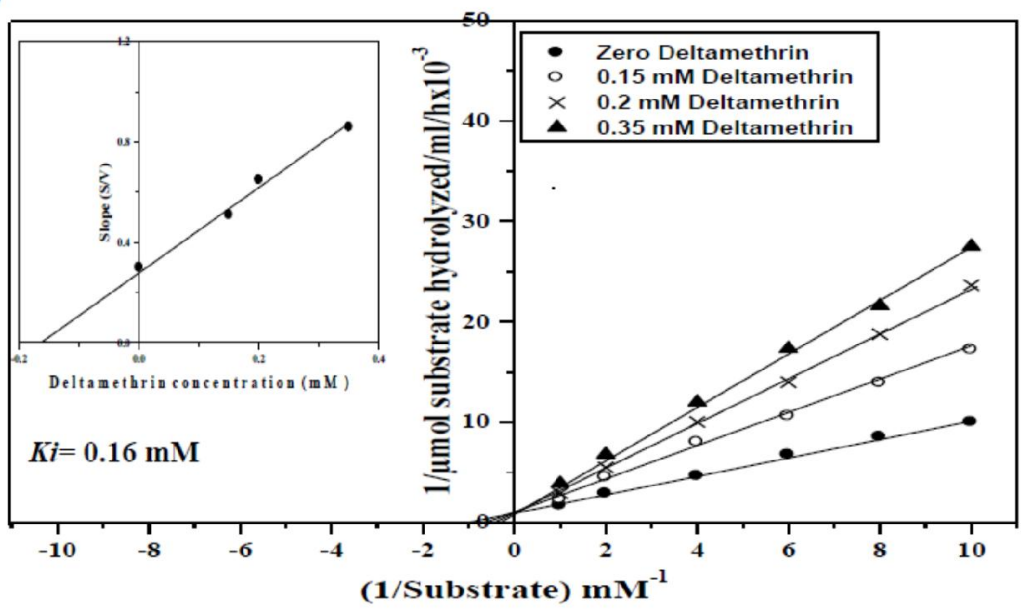

(b)

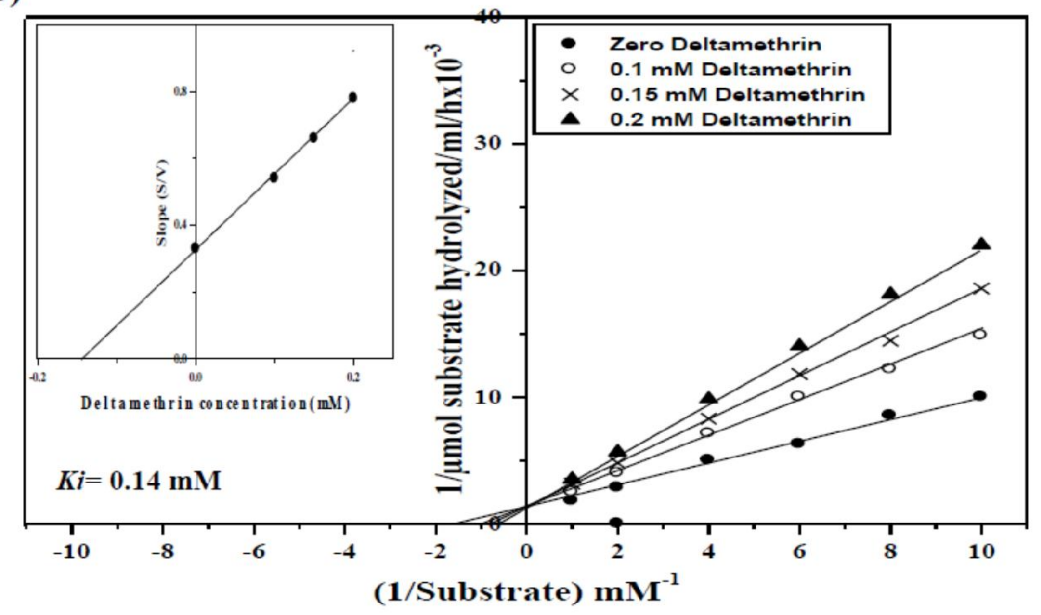

Fig. 10: Reciprocal of initial velocities of (a) AChEIIb and (b) AChEIIIb versus reciprocal concentrations of AcSChI in presence of different concentrations of deltamethrin. $K i$ of deltamethrin was shown in the inset. 


\subsubsection{Susceptibility towards emamectin benzoate}

A reduction in $R$. ferrugineus AChEs, AChEIIb and AChEIIIb activities were recorded with increasing emamectin benzoate concentration (Fig. 11). Upon incubation of each with $0.6 \mathrm{mM}, 80 \%$ and $85 \%$ of the activities were lost with $\mathrm{IC}_{50}$ values 0.35 and $0.3 \mathrm{mM}$, respectively. Emamectin benzoate non-competitively inhibited $R$. ferrugineus AChEIlb and AChEIIIb with $K i$ values 0.47 and $0.23 \mathrm{mM}$, respectively (Figs. $12 \mathrm{a}, \mathrm{b}$ ).

\subsection{Susceptibility of $\boldsymbol{R}$. ferrugineus AChEs towards botanical extracts}

\subsubsection{Susceptibility towards $O$. europaea extract}

The susceptibility of $R$. ferrugineus AChEs to inhibition in vitro by different concentration of the O. europaea extract revealed that, above concentration $3 \mathrm{mg}$, O. europaea exerted a strong inhibitory effect. Such effect increased by increasing the extract concentration (Fig. 13). Upon incubation $R$. ferrugineus AChEIIb and AChEIIIb with $10 \mathrm{mg}$ of O. europaea for $15 \mathrm{~min}, 79 \%$ and $87 \%$ loss in enzyme activities were recorded and the $\mathrm{IC}_{50}$ values are 7 and $5 \mathrm{mg}$, respectively. Competitive inhibition mechanisms were established for $R$. ferrugineus AChEIIb and AChEIIIb with $K_{i}$ values 5 and $3.5 \mathrm{mg}$, respectively (Fig.14 a, b).

\subsubsection{Susceptibility towards $A$. indica extract}

$R$. ferrugineus AChEs are susceptible to inhibition by different concentrations of the $A$. indica extract where increasing in the inhibitory effect by increasing the botanical extract concentration (Fig. 15). R. ferrugineus AChEIIb showed higher susceptibility than AChEIIIb, where 69 and $58 \%$ of inhibition was recorded upon incubation with $16 \mathrm{mg}$ of $A$. indica, and the $\mathrm{IC}_{50}$ values are 14 and $12 \mathrm{mg}$, respectively. Noncompetitive inhibition mechanisms were estimated for $R$. ferrugineus AChEIIb and AChEIIIb with $K_{i}$ values 10 and $9 \mathrm{mg}$, respectively (Fig. $16 \mathrm{a}, \mathrm{b}$ ).

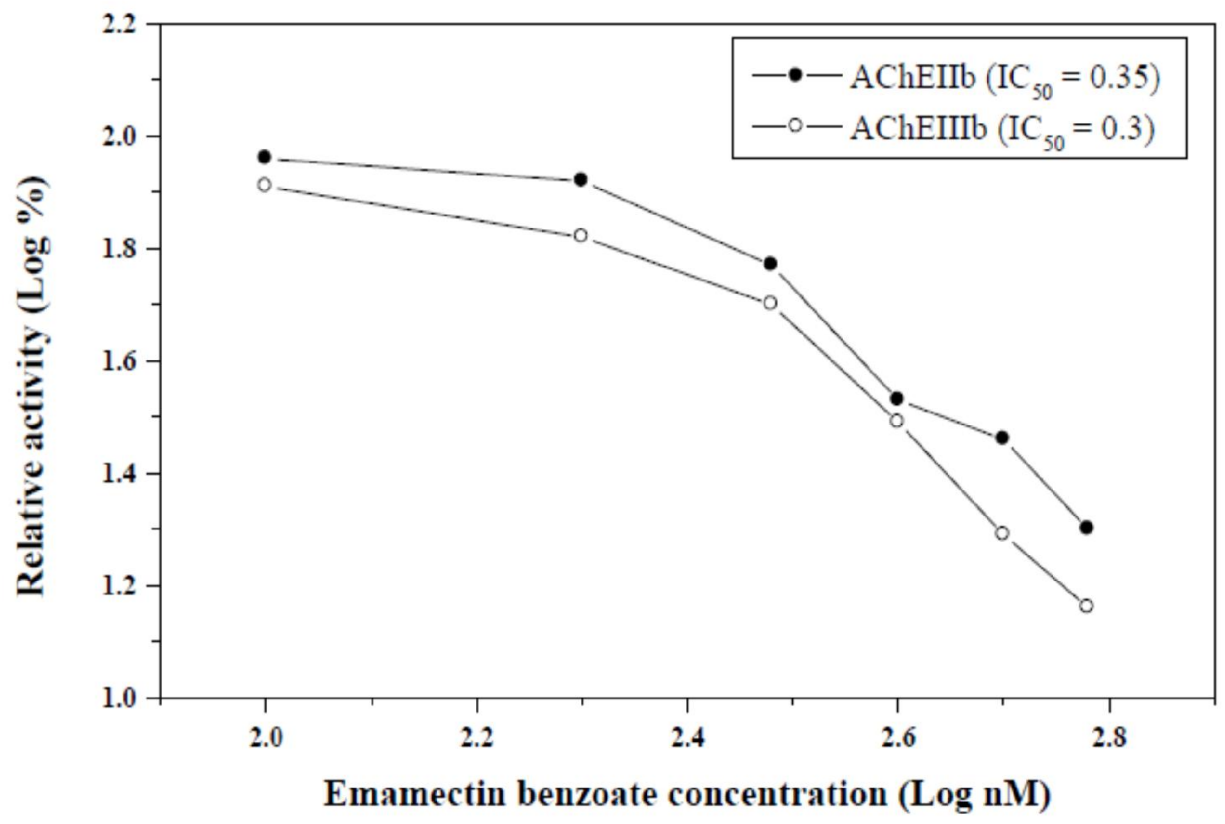

Fig. 11: Effect of different emamectin benzoate concentrations on the activities of $R$. ferrugineus AChEs. Purified AChEIIb and AChEIIIb were incubated for 15 min with different emamectin benzoate concentrations ranging from $0.1-0.6 \mathrm{mM}$ at room temperature followed by estimating the residual activities. 
(a)

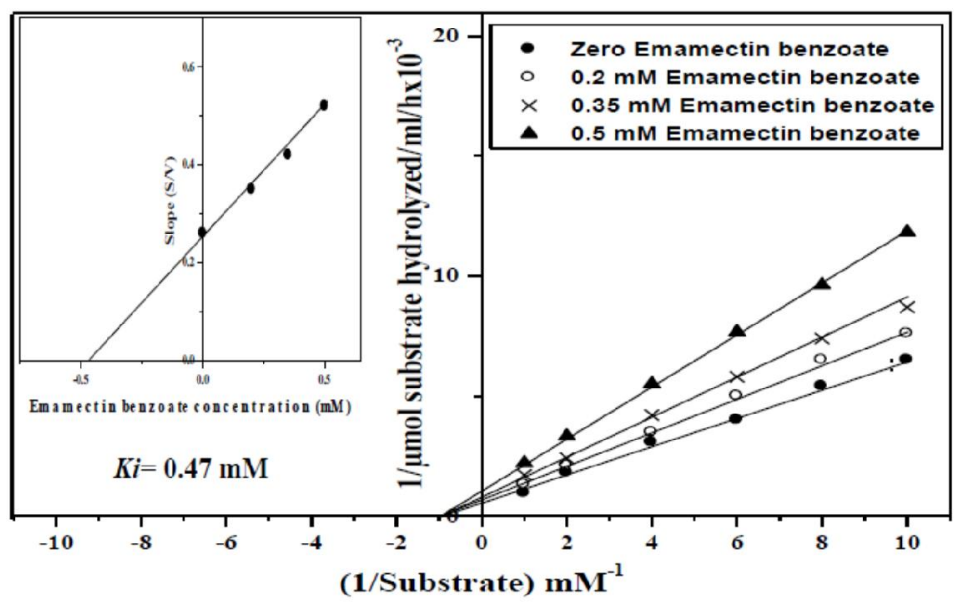

(b)

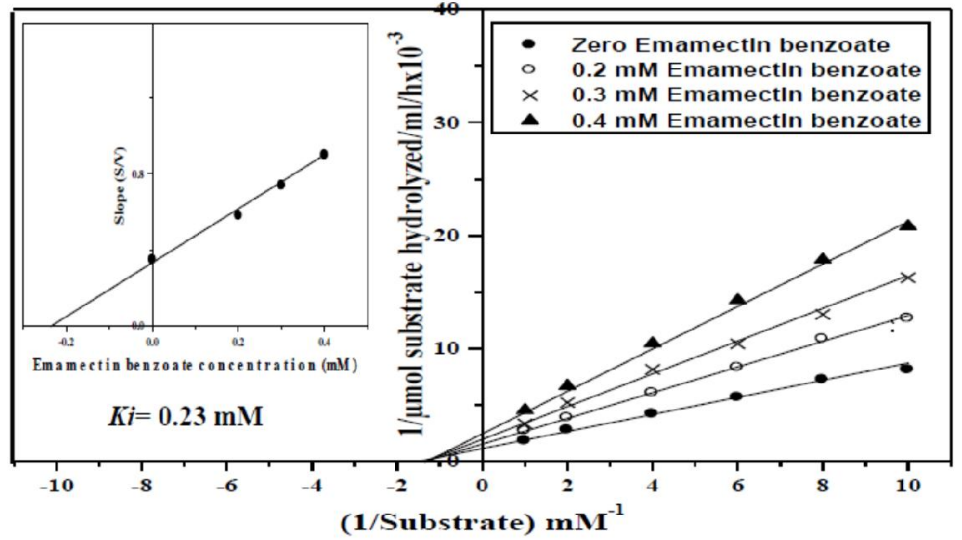

Fig. 12: Reciprocal of initial velocities of (a) AChEIIb and (b) AChEIIIb versus reciprocal concentrations of AcSChI in presence of different concentrations of emamectin benzoate. Ki of emamectin benzoate was shown in the inset.

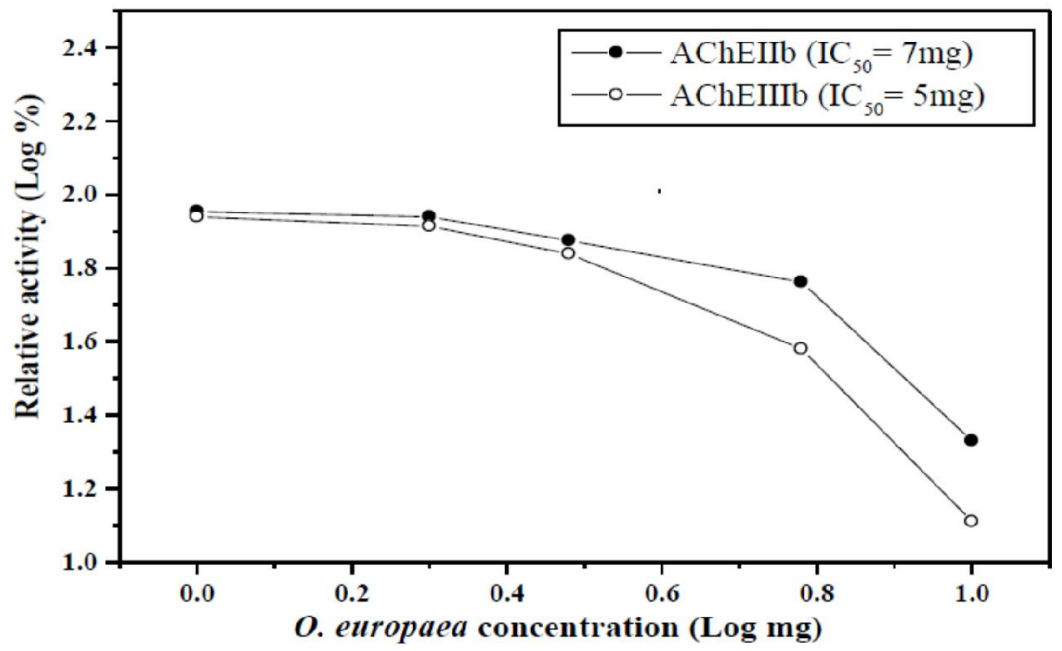

Fig. 13: Effect of different $O$. europaea concentrations on the activities of $R$. ferrugineus AChEs. Purified AChEIIb and AChEIIIb were incubated for 15 min with different $O$. europaea concentrations ranging from 1 to $10 \mathrm{mg}$ at room temperature followed by estimating the residual activities. 
(a)

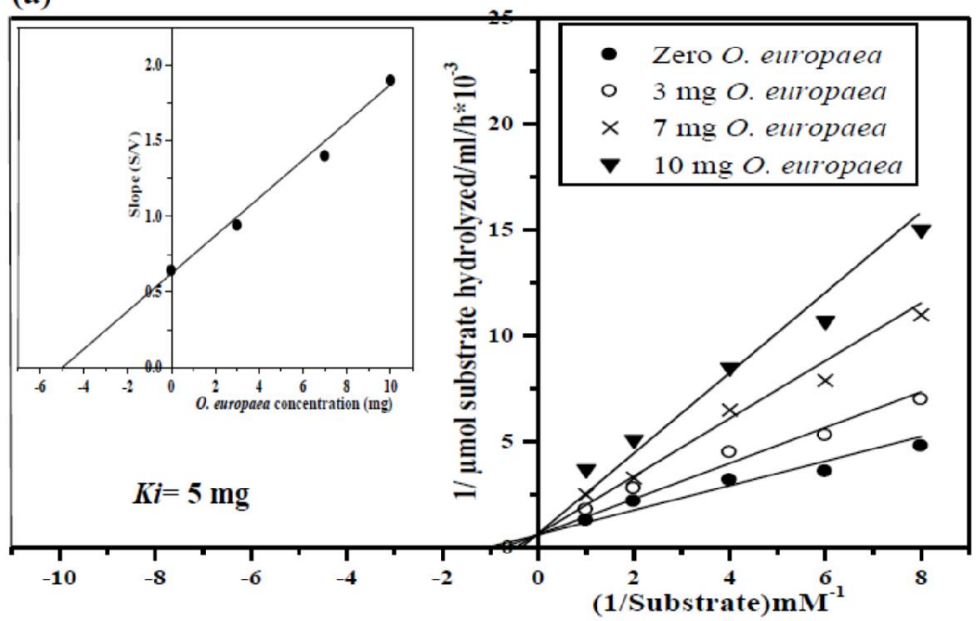

(b)

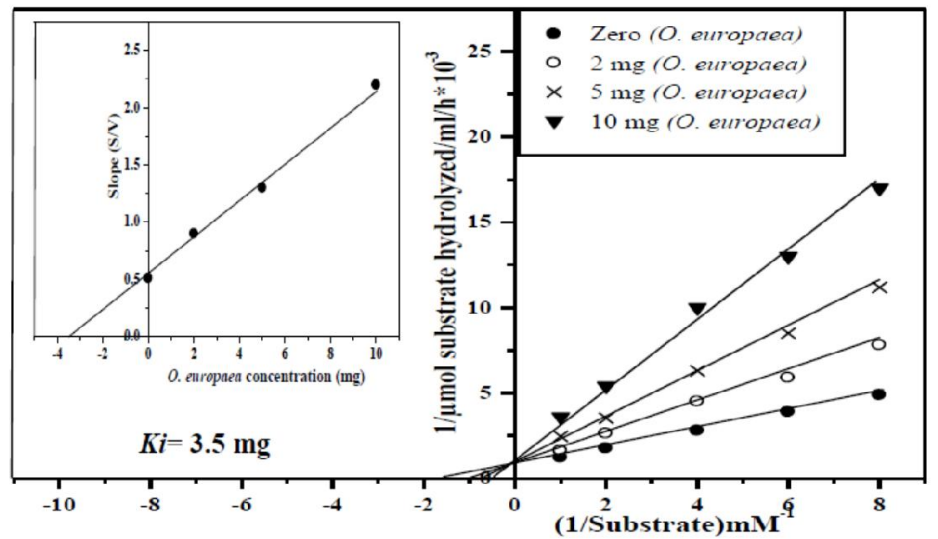

Fig. 14: Reciprocal of initial velocities of (a) AChEIIb and (b) AChEIIIb versus reciprocal concentrations of AcSChI in presence of different concentrations of $O$. europaea. Inhibition constant $(\mathrm{Ki})$ of $O$. europaea was shown in the inset.

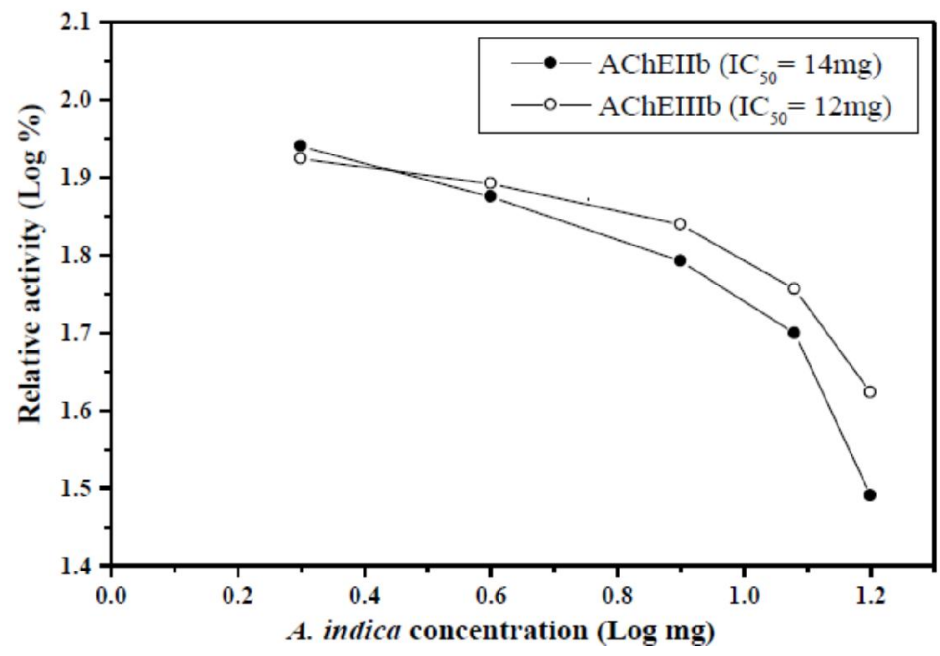

Fig. 15: Effect of different $A$. indica concentrations on the activities of $R$. ferrugineus AChEs. Purified AChEIIb and AChEIIIb were incubated for 15 min with different $A$. indica concentrations ranging from 2 to $16 \mathrm{mg}$ at room temperature followed by estimating the residual activities. 
(a)

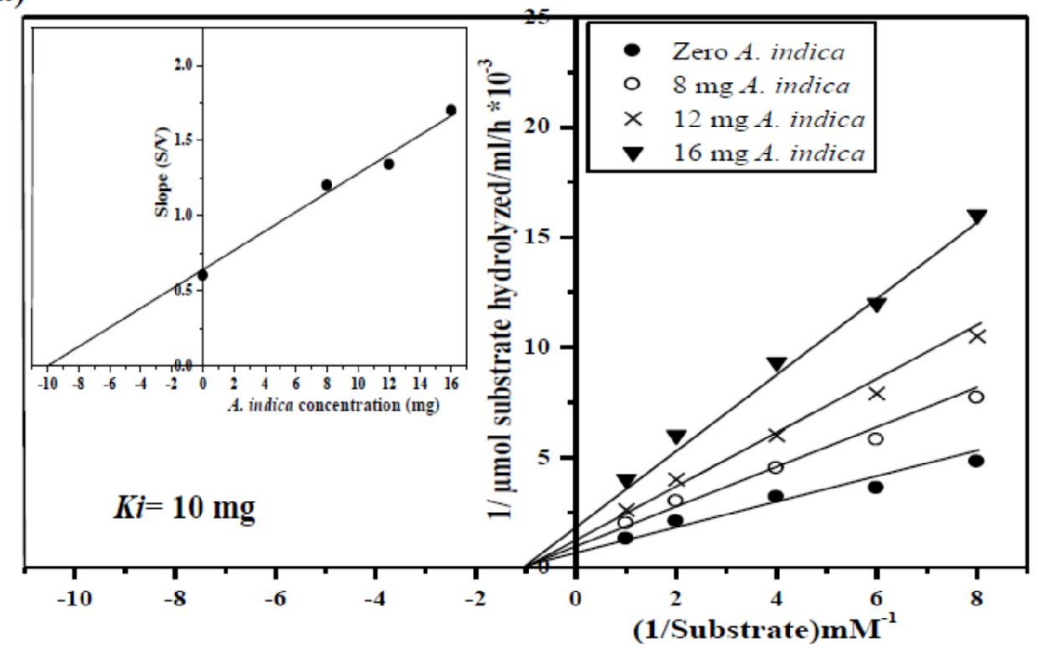

(b)

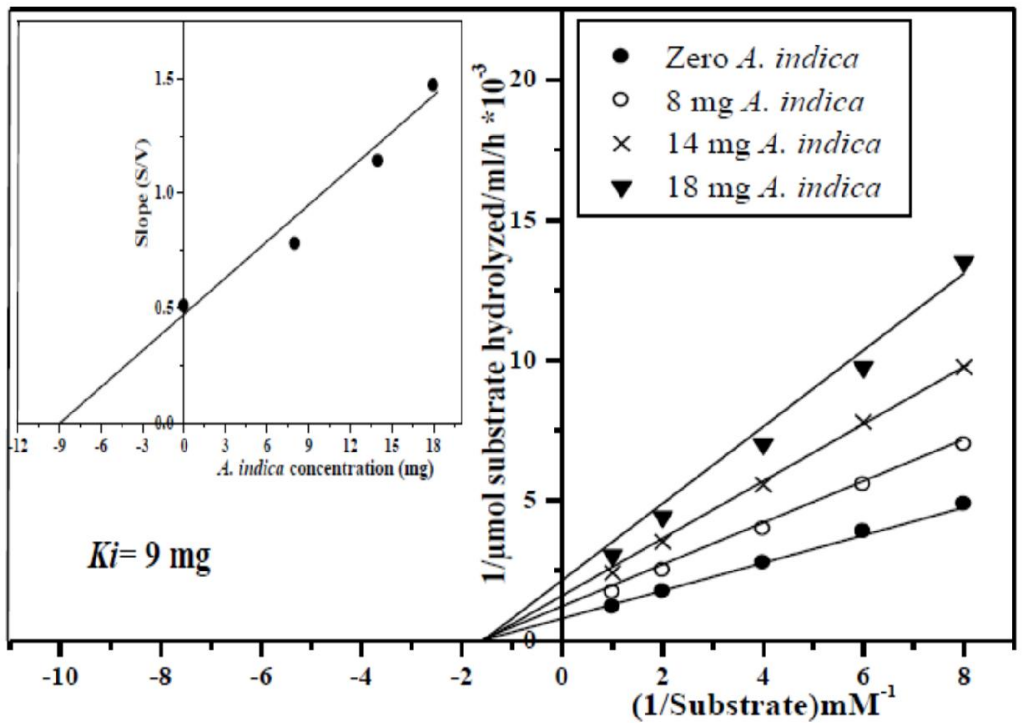

Fig. 16: Reciprocal of initial velocities of (a) AChEIIb and (b) AChEIIIb versus reciprocal concentrations of $\mathrm{AcSChI}$ in presence of different concentrations of $A$. indica. Inhibition constant $(K i)$ of $A$. indica was shown in the inset.

\subsubsection{Susceptibility towards $O$. basilicum}

The susceptibility of $R$. ferrugineus AChEs to inhibition by $O$. basilicum revealed that the inhibitory effect increased with regard to the botanical extract concentration (Fig. 17). Upon incubation with $30 \mathrm{mg}$ of $O$. basilicum, 77 and $71 \%$ of $R$. ferrugineus AChEIIb and AChEIIIb activities were suppressed with $\mathrm{IC}_{50}$ values 15 and $20 \mathrm{mg}$, respectively. Noncompetitive inhibition mechanisms (Figs $18 \mathrm{a}, \mathrm{b})$ were deduced with $K_{i}$ values 12 and $14 \mathrm{mg}$, respectively. The inhibition kinetic parameters, $\mathrm{IC}_{50}$ and $K_{i}$, and the mechanisms of inhibition of $R$. ferrugineus AChEs by different plant extracts are cumulative in Table (2).

\subsection{The active compounds present in $O$. europaea}

The active compounds present in the ethanolic leaves extract of $O$. europaea, as the promising botanical extract for inhibiting $R$. ferrugineus AChEs, by HPLC analysis are demonstrated. The fragmentation patterns of the peaks were compared with those of standards (Fig. 19). Thirteen peaks of active compounds are present in the extract with percent ranged from $0.05-96.8 \%$. Only, oleuropein is 
the major active compound and represented $96.8 \%$ Table (3).

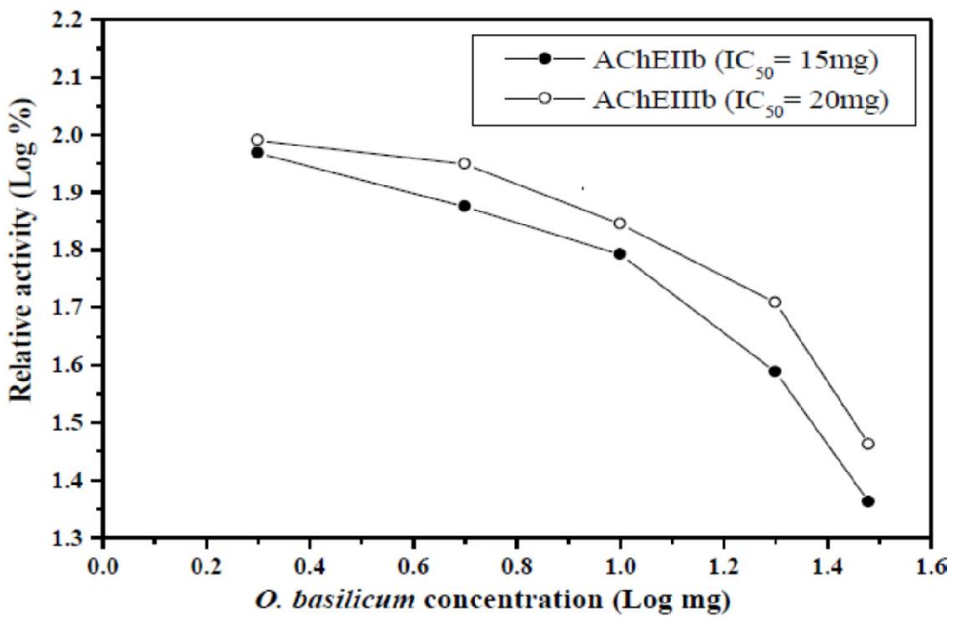

Fig. 17: Effect of different $O$. basilicum concentrations on the activities of $R$. ferrugineus AChEs. Purified AChEIIb and AChEIIIb were incubated for $15 \mathrm{~min}$ with different $O$. basilicum concentrations ranging from 2 to $30 \mathrm{mg}$ at room temperature followed by estimating the residual activities.

(a)

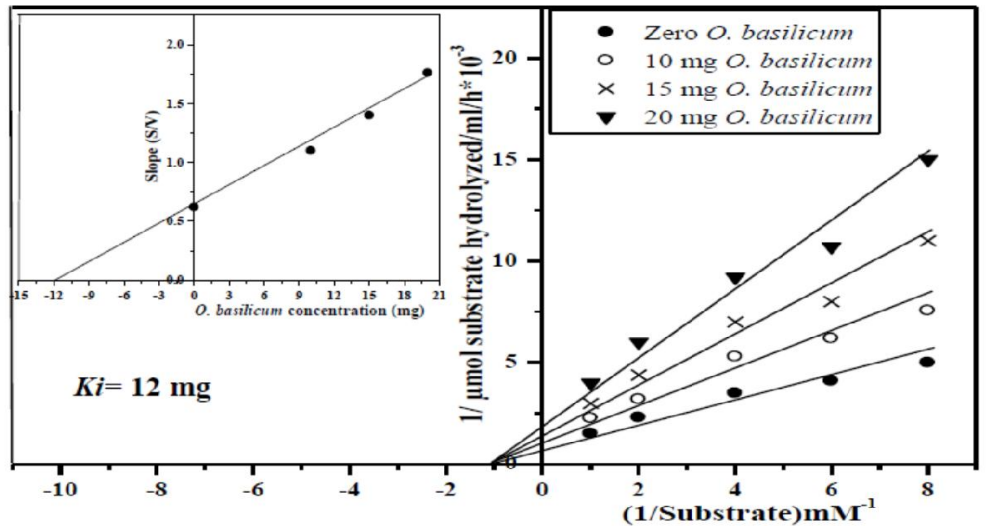

(b)

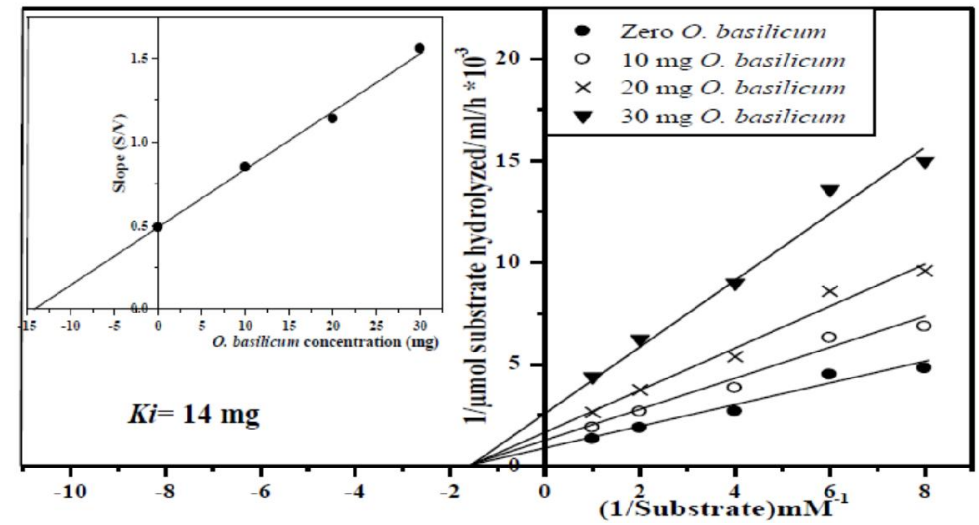

Fig. 18: Reciprocal of initial velocities of (a) AChEIIb and (b) AChEIIIb versus reciprocal concentrations of $\mathrm{AcSChI}$ in presence of different concentrations of $O$. basilicum. Inhibition constant $(\mathrm{Ki})$ of $O$. basilicum was shown in the inset. 


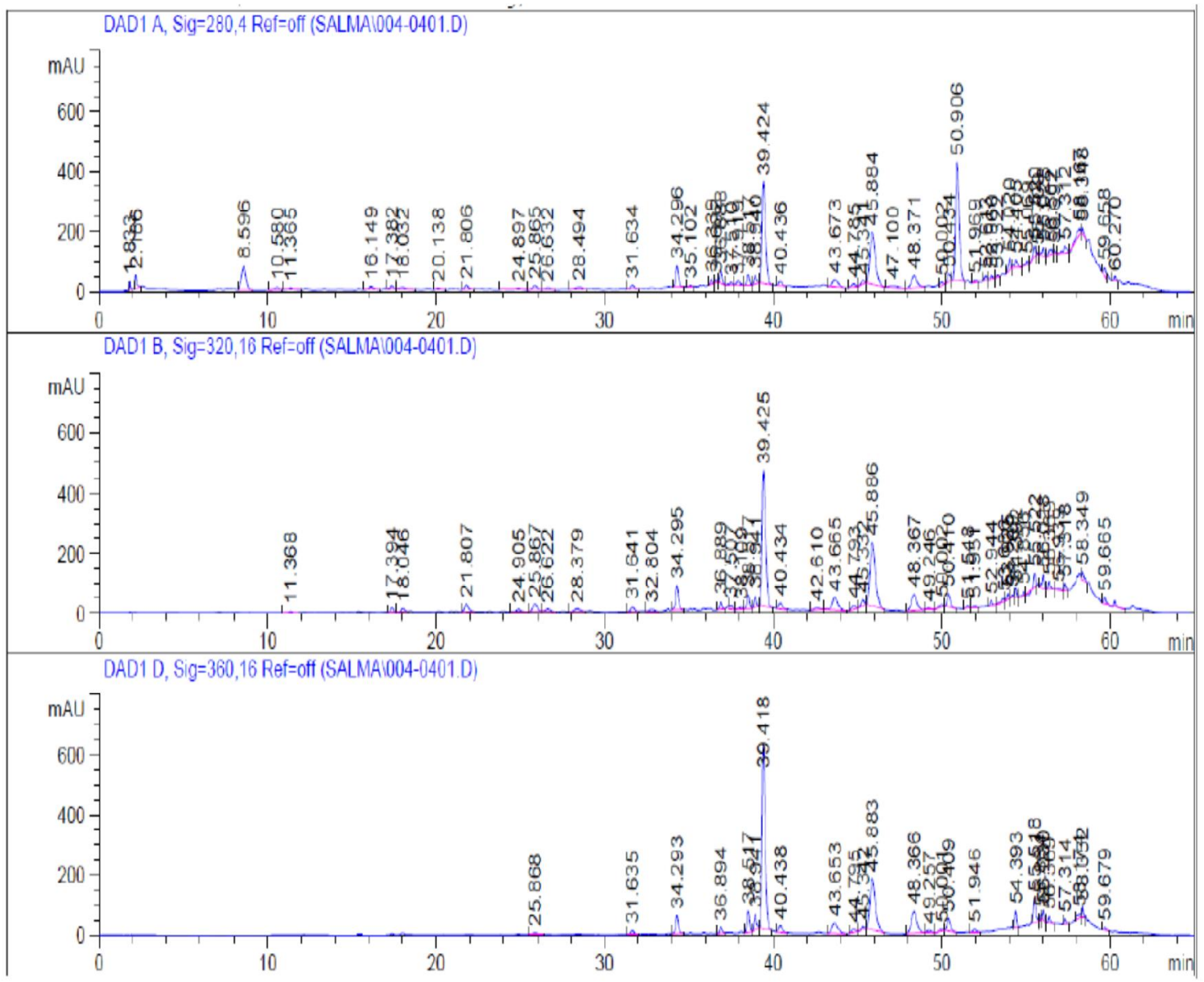

Fig. 19: HPLC- chromatogram of ethanol extract of $O$. europaea

Table 2: Kinetic parameters and mechanism of inhibition for inhibiting $R$. ferrugineus AChEs by different botanical extracts

\begin{tabular}{lcccc}
\hline \multirow{2}{*}{ Plant species } & \multicolumn{2}{c}{ IC $_{50}(\mathbf{m g})$} & \multicolumn{2}{c}{ Ki $(\mathbf{m g})$} \\
\cline { 2 - 5 } & AChEIIb & AChEIIIb & AChEIIb & AChEIIIb \\
\hline Olea europaea & 7 & 5 & $5^{\mathrm{c}}$ & $3.5^{\mathrm{c}}$ \\
Azerachita indica & 14 & 12 & $10^{\mathrm{n}}$ & $9^{\mathrm{n}}$ \\
Ocimum basilicum & 15 & 20 & $12^{\mathrm{n}}$ & $14^{\mathrm{n}}$ \\
\hline
\end{tabular}

c: Competitive

n: Non-competitive

Table 3: Active compounds present in the leaves extract of $O$. europaea using HPLC analysis

\begin{tabular}{ccc}
\hline No & Compound name & \% \\
\hline $\mathbf{1}$ & Gallic & 0.000 \\
$\mathbf{2}$ & Protocatechuic & 0.000 \\
$\mathbf{3}$ & $\rho$-hydroxybenzoic & 0.000 \\
$\mathbf{4}$ & Gentisic & 0.000 \\
$\mathbf{5}$ & Cateachin & 0.70 \\
$\mathbf{6}$ & Chlorogenic & 0.134 \\
$\mathbf{7}$ & Caffeic & 0.054 \\
$\mathbf{8}$ & Syringic & 0.074 \\
$\mathbf{9}$ & Vanillic & 0.104 \\
$\mathbf{1 0}$ & Ferulic & 0.05 \\
$\mathbf{1 1}$ & Sinapic & 0.384 \\
$\mathbf{1 2}$ & $\rho$-coumaric & 0.348 \\
$\mathbf{1 3}$ & Rutin & 0.96 \\
\hline
\end{tabular}




\begin{tabular}{lcc}
\hline $\mathbf{1 4}$ & & \\
$\mathbf{1 5}$ & Naringin & 0.000 \\
$\mathbf{1 6}$ & Oleuropein & $\mathbf{9 6 . 8}$ \\
$\mathbf{1 7}$ & Cinnamic & 0.064 \\
$\mathbf{1 8}$ & Quercetin & 0.234 \\
$\mathbf{1 9}$ & Kaempferol & 0.091 \\
\hline
\end{tabular}

\section{Discussion}

Current tactics employed to manage $R$. ferrugineus are largely based on chemical insecticides application. The choice of the chemicals used in the field regularly was developed through laboratory experiments (Shawir et al., 2014). Although chemical insecticides have been used for controlling RPW for long time, there is scarcity of knowledge for estimating the inhibitory effects of these insecticides and the mechanisms of inhibition on $R$. ferrugineus AChEs as the target site for inhibition and is responsible for the intoxication resulting in the target pest death. In addition, the usage of botanical extracts from different plant species as toxic compounds alternative to chemical insecticides through an integrated pest management (IPM) programs for management RPW have been investigated. The toxic effects of the ethanolic extract of Juniperus communis (Sharaby and Al-Dosary, 2014; 2016), A. indica (Bream et al., 2001) and O. basilicum (Ali et al., 2019) on different stages of RPW in vivo have been investigated. However, the information about the mode of action of the plant base insecticides is still so scanty.

This is the first report for evaluating the susceptibility of purified $R$. ferrugineus AChEs to inhibition by different insecticides and botanical extracts in vitro, as the target site for inhibition, and estimating the inhibition parameters ( $\mathrm{IC}_{50}, K i$, and the mechanism of inhibition). Such study was carried out for understanding the mechanism of $R$. ferrugineus AChEs for scavenging different insecticides to provide opportunities to develop the control strategies for mitigating the resistance problem and for preventing the failure of an insecticide(s) for management RPW. The present report aimed to predict and nominate in vitro the insecticide (s) and the botanical extract (s) that have high inhibitory effect against AChEs of the target pest $R$. ferrugineus. These parameters could be reliable measures of RPW susceptibility to insecticides and botanical extracts, since no physiological variables are incorporated in the system.

The failure of the available insecticides for management RPW is complained by the farmers (AlAyedh et al., 2016). This could be due to the development of insecticide resistance. Target-site insensitivity of $\mathrm{AChE}$ is a physiological mechanism for conferring resistance in different insect species by metabolic detoxification of synthetic insecticides (Pethuan et al., 2007; Kim et al., 2012; Dang et al., 2017).

R. ferrugeneus AChEs were susceptible to inhibition by all the insecticides examined, albeit weak with $\mathrm{IC}_{50}$ values ranged from 0.16 to $1.5 \mathrm{mM}$. Deltamethrin recorded the lowest $\mathrm{IC}_{50}$ values 0.2 and 0.15 $\mathrm{mM}$ for AChEIIb and AChEIIIb, respectively. On the contrary, malathion recorded the highest $\mathrm{IC}_{50}$ of 1.5 and $1.2 \mathrm{mM}$, respectively. Based on $\mathrm{IC}_{50}$ and $K i$, our data showed that $R$. ferrugeneus AChEs have similar susceptibility to inhibition by the examined insecticides and the potency of inhibition could be arranged as follows; deltamethrin $>$ carbosulfan $>$ oxamyl $>$ emamectin benzoate $>$ chloropyrifose $>$ malathion. A significant difference in susceptibility of $R$. ferrugeneus AChEs could be observed among the examined insecticides where, the susceptibility of $R$. ferrugeneus AChEs towards deltamethrin is in average 7.5- and 8.0-fold higher than that of malathion.

The inhibition parameters, $\mathrm{IC}_{50}$ and $K i$, values for $R$. ferrugineus AChEs towards different insecticides examined demonstrate that the highest and the lowest susceptibility of $R$. ferrugeneus AChEs towards insecticides was observed for deltamethrin and malathion, respectively. The inhibition kinetic parameters have been compared with those previously reported for different insect species (Table 1). Except for malathion and emamectin benzoate, all the insecticides examined competitively inhibited $R$. ferrugeneus AChEs with $K i$ values ranged from 0.16 to $1.2 \mathrm{mM}$.

This type of inhibition, competitive, decrease the $K m$ values of $R$. ferrugineus AChE. Since the $\mathrm{Km}$ has an inverse relationship with the substrate concentration required to saturate the active sites of the enzyme, this indicates that most of the insecticides, i.e., chlorpyrifos, oxamyl, carbosulfan and deltamethrin, decreased the affinity of $R$. ferrugineus AChEs towards substrate. In other words, $K m$ is the measurement of the stability of the enzyme-substrate complex, a high $\mathrm{Km}$ indicate weak binding and 
vice versa. While, the type of inhibition, non-competitive, diminished the Vmax of R. ferrugineus AChEs which refer that the presence of malation and emamectin benzoate, interfere with the rate of breakdown of the enzyme-substrate complex as deduced by Zibaee, (2011).

Chemical structure of the insecticide is significantly important for determining the susceptibility of AChEs to inhibition by insecticides (Shi et al., 2002). R. ferrugineus AChEs have high $\mathrm{IC}_{50}$ and $K i$ values for malathion and chloropyrifos. It can be concluded that $R$. ferrugineus AChEs, have the lowest sensitivity to inhibition by malathion and chloropyrifos, OP insecticides, with several folds than those for various insect species (Loewenstein et al., 1993; Villatte et al., 1998; Gaaboub et al., 2005; Wu et al., 2011). While chloropyrifos competitively inhibited $R$. ferrugineus AChEs, it noncompetitively inhibited laborartory and field strains of A. ipsilon and Apis millefra AChEs (Gaaboub et al., 2005). Chloropyrifos do not directly inhibited AChE, but must first be metabolized (Chambers and Chambers, 1989; Timechalk et al., 2002; Gaaboub et al., 2005).

Therefore it can be interpreted that $R$. ferrugineus AChEs have the least susceptibility towards such insecticides that belong to OP insecticides, justifying the concern of farmers regarding the low efficiency of these insecticides for management of RPW and could explain the lower efficiency of such insecticides upon field trail treatments. The insensitivity of $R$. ferrugineus AChEs may play a critical role in the tolerance of RPW to these insecticides. These results are congruent to that reported by Shawir et al. (2014) where insecticides belonging to OP group, chloropyrifos and dimethoate, have the least relative toxicity $\mathrm{LC}_{50}$ and are the least toxic insecticides against RPW.

Based on $\mathrm{IC}_{50}$ values, $R$. ferrugineus AChEIIb and AChEIIIb are 2.1- and 3.3- fold more susceptible to emamectin benzoate than chloropyrifos as an OP insecticide. These results confirmed the in vivo finding by Shawir et al. (2014), where emamectin benzoate had remarkable effect on the larvae of $R$. ferrugineus and the relative toxicity of emamectin benzoate at the level of $\mathrm{LD}_{50}$ was about 18.5times of chloropyrifos. In addition, Al-Jabr et al. (2013) found that emamectin benzoate was also a highly toxic insecticide and resulted in $92 \%$ cell mortality of mid-gut cell line of $R$. ferrugineus and $74 \%$ growth inhibition. Emamectin benzoate is a novel semi-synthetic derivative of natural product a barmectin in Avermactin family. It blocks post-synaptic potentials of the neuromuscular junction, leading to paralysis and finally the death of the target pest (Putter et al., 1981; Abdel-Aziz, 2019). The low inhibitory effect of chloropyrifos is in accordance to the interpretation recorded by Gaaboub and coworkers where, chloropyrifos exerted a weak inhibitory effect against AChEs of cotton leafworm, Spodoptera littoralis, cutworm, Agrotis ipsilon and honey bee Apis millefra (Gaaboub et al., 2005).

Studies of the inhibition kinetic of $R$. ferrugineus AChEs by different insecticides in vitro appear to be a useful tool to make a rational selection of the promising and the most efficient insecticides for management of RPW. AChE is the target of many OP and carbamate insecticides. The accepted mode of their action is the promotion of the phosphorylation or carbamylation type modifications of the active site of the AChEs. These modifications inhibit AChE activity and block the hydrolysis of ACh (Hsu et al., 2008). This step results in an increase ACh level at the nerve fibers and the eventual failure of nerves to repolarize and eventually the death of the insect. In the present study, the results of in vitro inhibition of RPW AChEs by insecticides as OPs, carbamates, pyrethroids and avermectins agreed quite well with the previously published in vivo bioassays data (Shawir et al., 2014).

The insecticidal activity of sweet basil, $O$. basilicum against $R$. ferrugineus has been evaluated and the major essential oil components are: methyl chavicol (estragole) (27.82\%), linalool (25-35\%), eugenol (8.81\%), eualyptol (4.92\%) and terpinen (2.1\%) (Abdel Kareim et al., 2017). Eugenol, the principle compound of the essential oils of basil, has a strong repellent activity against insect pests. Linalool is the second eventual oil present also in basil has toxic effect to the Bruchid zabrotes subfasciatus and other storage pests (Weaver et al., 1991; Kim and Lee, 2014). Recently, Ali et al. (2019) documented the insecticidal potential of basil against different stages of RPW and concluded that $O$. basilicum could be used for management RPW in the egg and larva stages. The present study represents the first report to establishment the susceptibility of purified $R$. ferrugineus AChEs to inhibition by $O$. basilicum extract. $O$. basilicum extract inhibited $R$. ferrugineus AChEIIb and AChEIIIb noncompetitively with $K i$ value 12 and $14 \mathrm{mg}$ and with $\mathrm{IC}_{50}$ values 15 and $20 \mathrm{mg}$, respectively.

$A$. indica has long been recognized as a source of environment friendly biopesticide. The high insecticidal effect of neem leaves extract could be attributed to the presence of various compounds that are lethal to a wide range of insects and their complex mode of action (Schmutterer, 1990). Its physiological and insecticidal effects against Lepidopteran insects have been reviewed (Senthil-Nathan, 
2013). Leaves extract showed marked insect control potential and can be recommended for many IPM programs (Khan et al., 2007; Senthil-Nathan, 2013; Rana et al., 2015; Abd-Elsalam et al., 2016). The insecticidal effect of neem extract $A$. indica on the respiratory metabolism during the pupal stage of RPW R. ferrugineus (Bream et al., 2001) has been investigated.

The present study demonstrated a significant $(\mathrm{P}<0.01)$ reduction in $R$. ferrugineus $\mathrm{AChEIIb}$ and AChEIIIb activities, where 69 and $58 \%$ of the enzyme activities were inhibited by $16 \mathrm{mg}$ of $A$. indica, respectively. A. indica noncompetitively inhibited $R$. ferrugineus AChEIIb and AChEIIIb with $K_{i}$ values 10 and $9 \mathrm{mg}$, respectively. Similarly, A. indica leaves extract suppressed Musca domestica (Rana et al., 2015 ) and Drosophila melanogaster AChEs (Khan et al., 2007) with $20.35 \%$ and $45 \%$ inhibition in presence of 16.4 and $16.9 \mu \mathrm{g} / \mathrm{ml}$, respectively. Senthil-Nathan et al. (2008) reported that the active ingredients from $A$. indica alter $\mathrm{AChE}$ activity and the $\mathrm{LC}_{50}$ concentration of $A$. indica significantly inhibited AChE activity of the brown plant hopper, Nilaparvata lugens. However, certain essential oils from aromatic plants, monoterpenes, competitively inhibited AChE in vitro (Grundy and still, 1985; Miyazawa, et al., 1997).

R. ferrugineus AChEIIb and AChEIIIb have high susceptibility to inhibition by $O$. europaea leaves extract with $\mathrm{IC}_{50}$ values 7 and $5 \mathrm{mg}$, respectively. According to the $\mathrm{IC}_{50}$, O. europaea extract exerted the highest inhibitory effect where, the susceptibility of the enzymes ranged from 2.0-4.0-fold higher than that recorded for $A$. indica and $O$. basilicum. The most promising botanical extract for inhibition $R$. ferrugineus AChEs is $O$. europaea. $O$. europaea extract competitively inhibited $R$. ferrugineus AChEs. This revealed that $O$. europaea extract decreased the affinities of $R$. ferrugineus AChEs to the substrate and weak binding of the enzymes to the substrate.

The mode of action of the botanical extracts, as bioinsecticides is not obviously known. However, it is evident that botanical extracts affect insect physiology as; repellent, antifeedant and growth regulation effects, in diverse ways. Botanical extract constituents affect biochemical processes, which specifically disrupt the endocrinologic balance of insects (Rattan, 2010; Kumar et al., 2011), blocked insect AChEs synthesis by which play role in cholinergic synapses in insects and higher animals (Fournier and Mutero, 1994; Kumar et al., 2011) for nerve conduction and thus maintain a general coordination in the neuromuscular system. However, this action may not be correlated with toxicity to insects in vivo where a direct correlation between insect toxicity and AChE inhibition could not be recorded (Lee et al. 2001; Isman, 2000).

The HPLC analysis for O. europae, as the promising botanical extract with the highest inhibitory effect on $R$. ferrugineus AChEs, showed that oleuropein constitutes the highest percentage (96.8) of the total compounds present in $O$. europae. The inhibitory effect of $O$. europae may be attributed to the active compounds that are contained in the extract. Rajashekar et al. (2014) reported that the active compounds of the botanical extract have broad impact across the nervous system which is attenuated by modified acetyl choline and acetate function.

In conclusion, the susceptibility of $R$. ferrugineus AChEs toward different insecticides appear to be a useful tool in vitro approach for selecting the most promising insecticides for controlling RPW. $R$. ferrugineus AChEs have the least sensitivity towards malathion and chloropyrifos as OP insecticides, and this can justify the complaint by the farmers regarding the low efficiency of these insecticides for controlling RPW. The combination of the promising insecticide, deltamthrin, and $O$. europaea extract will be investigated in future, in vivo, for estimating the synergistic relation between them for management of $R$. ferrugineus, reducing the amounts of insecticides released in the environment and as an attempt to increase their efficacy against RPW to overcome the failure of synthetic insecticide(s) upon field application for controlling $R$. ferrugineus.

\section{Acknowledgments}

This work was supported by Molecular Biology department at the National Research Center in Egypt. 


\section{References}

Abdel Aziz, M.F., 2019. Effects of some insecticide mixtures on toxicity and some biochemical parameters of cotton leafworm, Spodoptera littoralis (Boisd.). Egypt. Acad. J. Biolog. Sci., 11: 139-148.

Abdel Kareim, A.I., A.M. Mohamed, A.A. Rashed, F.M. Said, M.A. Qasim, and S.M. Mohsen, 2017. Oviposition deterrent effect of four essential oils against the date palm weevil, Rhynchophorus ferrugineus Olivier. Middle East J. Agricul. Res., 6: 1336-1345.

Abdelsalam, S.A., A.M. Alzahrani, O.M. Elmenshawy et al., 2016.Spinosad induces antioxidative response and ultrastructure changes in males of red palm weevil Rhynchophorus ferrugineus (Coleoptera: Dryophthoridae). Journal of Insect Science 16:106.

https://doi.org/10.1093/jisesa/iew089

Al-Ayedh, H., A. Hussain, M. Rizwan-ul-Haq, and A. M. Al-Jabr, 2016. Status of insecticide resistance in field-collected populations of Rhynchophorus ferrugineus (Olivier) (Coleoptera: Curculionidae). Intern. J. Agric. Biol., 18: 103-110.

Ali, M.A., K.M. Mohanna, G.S. Mohamed, and R.O.H. Allam, 2019. Efficacy of some promising plant essential oils to control the red palm weevil Rhynchophorus ferrugineus Olivier (Coleoptera: Curculionidae) under laboratory conditions. IJAS. 1: 12-22.

Al-Jabr, A.M., M. Rizwan-ul-Haq, A. Hussain, A.I. Al-Mubarak, and H.Y. Al-Ayied, 2013. Establishing midgut cell culture from Rhynchophorus ferrugineus (Olivier) and toxicity assessment against ten different insecticides. In Vitro Cell. Dev. Biol. Anim., 50: 296-303.

Alzahrani, A.M., 2019. Ultrastructural damage and biochemical alterations in the testes of red palm weevils (Rhynchophorus ferrugineus) exposed to imidacloprid. Environ. Sci. Pollut. Res. Int. 26:16548-16555. doi: 10.1007/s11356-019-04968-8

Bamidele, O. S., J.O. Ajele, and F.M. Olajuyigbe, 2017. An evaluation of glutathione transferase associated with dichlorvos degradation in African palm weevil (Rynchophorus phoenicis) larva. Cogent Biol., 3: 1286764.

Bamidele, O., J. Ajele, A. Kolawole, and O. Akinkuolere, 2013. Changes in the tissue antioxidant enzyme activities of palm weevil (Rynchophorous phoenicis) larva by the action of 2,2dichlorovinyl dimethyl phosphate. Afr. J. Biochem. Res., 7: 128-137.

Begum, N., B. Sharma, and R.S. Pandey, 2010. Toxicity potential and anti AchE activity of some plant extracts in Musca Domestica. Journal Biofertilizers and Biopesticides, 2:108-113.

Bream, A.S., K.S. Ghoneim, M.A. Tanani, and M.M. Nassar, 2001. Respiratory metabolic responsiveness during the pupal stage of the red palm weevil, Rhynchophorus ferrugineus (Coleoptera: Curculionidae) to certain plant extracts. Med. Fac. Landbouww. Univ. Gent, Belgium., 66: 491-502.

Breuer, M., B. Hoste, A. De Loof, and S.N.H. Naqvi, 2003. Effect of Melia azedarach extract on the activity of NADPH-cytochrome c reductase and cholinesterase in insects. Pesticide Biochemist. Physiol., 76: 99-103.

Chambers, J.E., and H.W. Chambers, 1989. Oxidative desulfuration of chlorpyrifos, chlorpyrifosmethyl, and leptophos by rat brain and liver. J. Biochem. Toxicol. 4:201-203.

Dang, K., S.L. Doggett, G. Veera Singham, and C.Y. Lee, 2017. Insecticide resistance and resistance mechanisms in bed bugs, Cimex spp. (Hemiptera: Cimicidae). Parasites and vectors. https://doi.org/10.1186/s13071-017-2232-3.

Devonshire, A.L. and G.D. Moores, 1982. Different forms of insensitive acetylcholinesterase in insecticide-resistant house flies, Musca domestica. Pest. Biochem. Physiol., 21: 336-340.

Dixon, M. and E.C. Webb, 1964. Enzymes, Longmans, and London, 950.

Ellman, G.R., K.D. Courtney, V. Andres, and R.M. Featherstone, 1961. A new and rapid colorimetric determination of acetylcholinesterase activity. Biochem. Pharmacol. 7: 88-95.

Fournier, D. and A. Mutero, 1994. Modification of acetylcholinesterase as a mechanism of resistance to insecticides. Comp. Biochem. Physiol., C. 108: 19-31.

Gaaboub, I., A.F. El-Aswad, and S. Halawaa, 2005. Kinetic investigation into the interaction of chlorpyrifos and thiodicarb with acetylcholinesterase activity from some harmful and beneficial insects. J. Egypt. Soc. Toxicol. 33: 71-78. 
Ghoneim, K.E., K.S. Hamadah, and A.A. El-Hela, 2012. Acetylcholinesterase activity in the desert locust Schistocerca gregaria (Acrididae) (Forsk.) as a response to the action of the wild herb Fagonia bruguieri DC. (Zygophyllaceae) extracts. J. Entomol. Res. Soc. 14: 87-97.

Grundy, D.L. and C.C. Still, 1985. Inhibition of acetylcholinesterases by pulegone-1,2-epoxide. Pesticide Biochem. Physiol. 23: 383-388.

Chen, H-J., Z. Liao, X-M. Hui, G-Q. Li, F. Li, and Z.-J. Han, 2009. Ace2, rather than Acel, is the major acetylcholinesterase in the silkworm, Bombyx mori". Insect Science, 16: 297-303.

Hsu, J. C., W.J. Wu, D.S. Haymer, H.Y. Liao, and H.T. Feng, 2008. Alterations of the acetylcholinesterase enzyme in the oriental fruit fly Bactrocera dorsalis are correlated with resistance to the organophosphate insecticide fenitrothion. Insect Biochem. Mol. Biol., 38: 146154.

Isman, M.B., 2000. Plant essential oils for pest and disease management. Crop Protection, 19: 603-608.

Khan, M.F., I. Ahmed, M. Jahan, N. Yasmin, S.S. Qadri and S.N.H. Naqvi, 2007. Toxicological studies of Methoprene (ZR 515) and Dicrotophos as compared to neem extract RB-b and estimation of cholinesterase against Drosophila melanogaster M. J. Exp. Zool. India, 10: 121-124.

Kim, K.H., R. Tsao, R. Yang, and S.W. Cui, 2006. Phenolic acid profiles and antioxidant activities of wheat bran extracts and the effect of hydrolysis conditions. Food Chem., 95(3): 466-473.

Kim, S.I. and D.W. Lee, 2014. Toxicity of basil and orange essential oils and their components against two coleopteran stored products insect pests. J. Asia-Pacific Entomol., 17:13-17.

Kim, Y.H., J.C. Deok, W.J. Je, W.K. Hyung, and H.L. Si, 2012. Molecular and kinetic properties of two acetylcholinesterases from the western honey bee, Apis mellifera. PLOS ONE 7: e48838.

Kim, Y.H., J.Y. Choi, Y.H. Je, Y.H. Koh, and S.H. Lee, 2010. Functional analysis and molecular characterization of two acetylcholinesterases from the German cockroach, Blattella germanica. Insect Mol. Biol., 19: 765-776.

Kolawole, A.O., F.M. Olajuyigbe, J.O. Ajele, and C.O. Adedire, 2014. Activity of the antioxidant defense system in a typical bioinsecticide-and synthetic insecticide-treated cowpea storage beetle Callosobrochus maculatus F. (Coleoptera: Chrysomelidae). Inte. J. Insect Sci., 6:99-108. https://doi.org/10.4137/IJIS.S19434.

Kumar, S., C.J. Seal, and E.J. Okello, 2011. Kinetics of acetylcholinesterase inhibition by an aqueous extract of Withania somnifera roots. Int. J. Pharm. Sci. Res., 2: 1188-1192.

Lee, B.-H., W.-S. Choi, S.-E. Lee, and B.-S. Park, 2001. Fumigant toxicity of essential oils and their constituent compounds towards the rice weevil, Sitophilus oryzae (L.). Crop. Protect. 20:317-320.

Loewenstein, Y., M. Denarie, H. Zakut, and H. Soreq, 1993. Molecular dissection of cholinesterase domains responsible for carbamate toxicity. Chemico-Biological Interactions, 87:209-216.

Mahmoud, E.A., T. Sileem, and R.S. Hassan , 2017. Morphological and electrophoretic differences between various patterns of Egyptian red palm weevils, Rhynchophorous ferrugineus. AJNSA. 50: 301-309.

Miyazawa, M., H. Watanabe, and H. Kameoka, 1997. Inhibition of acetylcholinesterase activity by monoterpenods with ap-menthane skeleton. J. Agricul. Food Chem., 45: 677-679.

Mohamed, M.A., E.M.E. Mahdy, A.E.M. Ghazy, N.M. Ibrahim, H.A. El-Mezayen, and M.M.E. Ghanem, 2017. Acetylcholinesterases from entomopathogenic nematode Heterorhabditid bacteriophora: Susceptibility to insecticides and immunological characteristics. Pesticide Biochemistry and Physiology, 135: 27-34.

Mohamed, M.A., S. Shaalan, A.M. Ghazy, A.A. Ali, A.M. Abd-Elaziz, M.M. Ghanem, and S.A. AbdElghany, 2020. Purification and characterization of acetylcholinesterases from red palm weevil Rhynchophorus ferrugineus. Int. J. Biol. Macromol., 147: 1029-1040.

Olmedo, R., J.M. Herrera, E.I. Lucini, M.P. Zunino, R.P. Pizzolitto, J.S. Dambolena, and J.A. Zygadlo, 2015. Essential oil of Tagetes filifolia against the flour beetle Tribolium castaneum and its relation to acetylcholinesterase activity and lipid peroxidation. Agriscientia., 32: 113-121.

Oni, M.O., C.O. Olaniyi, O.O. Samuel, S.B. Olufemi and I.O. Thomas, 2019. Inhibitory effects of oil extract of green Acalypha (Acalypha wilkesiana) on antioxidant and neurotransmitter enzymes in Callosobruchus maculatus. J. Bas. App. Zool. https://doi.org/10.1186/s41936-019-0116-0.

Pethuan, S., N. Jirakanjanakit, S. Saengtharatip, T. Chareonviriyaphap, D. Kaewpa, and P. Rongnoparut, 2007. Biochemical studies of insecticide resistance in Aedes Stegomyia aegypti and Aedes Stegomyia albopictus (Diptera: Culicidae) in Thailand. Trop. Biomed., 24: 7-15. 
Prakash, K.S.B., 2015. Toxicity and biochemical efficacy of chemically characterized Rosmarinus officinalis essential oil against Sitophilus oryzae and Oryzaephilus surinamensis. Industrial Crops and Products., 74: 817-823.

Putter, I., J.G. Macconnell, F.A. Preisery, A.A. Haidri, S.S. Ristich and R.A. Dybas, 1981. Avermactins: Novel Insecticides, acaricides and nematicides from a soil microorganism Experimentia, 37: 963964.

Rajashekar, Y., A. Raghavendra, and N. Bakthavatsalam, 2014. Acetylcholinesterase inhibition by biofumigant (Coumaran) from leaves of Lantana camara in stored grain and household insect pests. BioMed Research International. https://doi.org/10.1155/2014/187019.

Rana, H., M.F. Khan, M.F. Akbar, H.M. Tahir, M.S. Khan, and Z. Ahmed, 2015. Cholinesterase inhibition effects of Azadirachta indica a. juss fresh leaves extract and its effects on musca domestica L. larval mortality, pupation, adult emergence, fecundity and fertility. Int. J. Agric. Appl. Sci. 7: 28-36.

Rattan, R.S., 2010. Mechanism of action of insecticidal secondary metabolites of plant origin. Crop Protection, 29: 913-920.

Salama, H.S., M.S. Foda, M.A. El-Bendary, and A. Abdel-Razek, 2004. Infection of red palm weevil, Rhynchophorus ferrugineus, by spore-forming bacilliin digenous to its natural habitat in Egypt. J. Pest Sci., 77: 27-31.

Salem, S.A. and A.M. Abdel Salam, 2018. The optimal used of some types of natural food attractive as a tool to redice the prediction and limit the spread of red palm weevil Rhynchophorus ferrugineus Olivier. Biosci. Res. 15: 2911-2918.

Salem, S.A. and S.R. Ahmed, 2015. The relationship between environmental factors and cultyral practices and red palm weevil, Rhynchophorus ferrugineus Olivier infestation. Swift J. Agricul. Res. 1: 5-8.

Salem, S.A., 2015. Accuracy of trained dogs for early detection of red palm weevil, Rhynchophorus ferrugineus Olivie, infestations in date palm plantations. Swift J. Agricul. Res. 1: 1-4.

Salem, S.A., A.M.E. Abd El-Salam, M.A. Abdel-Raheem, N.A. Farage, and F.M. El-Hawary, 2016. Field studies to assess the efficiency of bio-extracts against the scourge of onion crops, Thrips tabaci Lindeman in Egypt. Der Pharma Chemica. 8: 74-77.

Santos, A.M.D., A.C. Moreira, B.R. Lopes, M.F. Fracola, F.G. Almeida, O.C. Bueno, Q.B. Cass, and D.H.F. Souza, 2019. Acetylcholinesterases from leaf-cutting ant atta sexdens: purification, characterization, and capillary reactors for on-flow assays. Enzyme Res., 6139863.

Schmutterer, H., 1990. Properties and potential of natural pesticides from the neem tree, Azadirachta indica. Annu. Rev. Entomol. 35: 271-297.

Senthil Nathan, S., M.Y. Choi, H.Y. Seo, C.H. Paik, K. Kalaivani, and J.D. Kim, 2008. Effect of azadirachtin on acetylcholinesterase (AchE) activity and histology of the brown planthopper Nilaparvata lugens (Stal). Ecotoxicol. Environmental Safety. 70: 244-250.

Senthil-Nathan, S., 2013. Physiological and biochemical effect of neem and other Meliaceae plants secondary metabolites against Lepidopteran insects. Front Physiol., 4:359. doi:10.3389/fphys.2013.00359.

Sharaby, A. and M. El-Dosary, 2014. An electric air flow olfactometer and the olfactory response of Rhynchophorous ferrugineus weevil to some volatile compounds. J. Agric. Ecol. Res. Inter. 1: 4050 .

Sharaby, A. and M. El-Dosary, 2016. Possibility using camphene as biorational insecticide against the red palm weevil Rhynchophorus ferrugineus (Colioptera: Curculionedae). IJSR 5: ART2016782.

Shawir, M.S., M.A. Abbassy, and Y.M. Salem, 2014. Laboratory evaluation of some insecticides against larval and adult stages of red palm weevil's Rhynchophorus ferrugineus (Olivier). Alex. Sci. exch. J. 35: 75-79.

Shi, M.A., J.Z. Yuan, J. Wu, P.J. Zhuang, X.F. Wu, and Z.H. Tang, 2002. Kinetic analysis of acetylcholinesterase in a propoxur-resistant strain of housefly, Musca domesticd, from Shanghai, China. Pest. Biochem. Physiol., 72: 72-82.

Timchalk, C., R.J. Nolan, A.L. Mendrala, D.A. Dittenber, K.A. Brzak, and J.L. Mattsson, 2002. A physiologically based pharmacokinetic and pharmacodynamic (PBPK/PD) model for the organophosphate insecticide chlorpyrifos in rats and humans. Toxicological Sciences. 66:34-53. 
Vatanparast, M., V. Hosseininaveh, M. Ghadamyari, and S.M. Sajjadian, 2014. Plant cell wall degrading enzymes, pectinase and cellulase, in the digestive system of the red palm weevil, Rhynchophorus ferrugineus (Coleoptera: Curculionidae). Plant Protect. Sci., 50: 190-198.

Vidyasagar, P.S., M. Hagi, R.A. Abozuhairah, O.E. Al-Mohanna, and A.A. Al-Saihati, 2000. Impact of mass pheromone trapping on red palm weevil adult population and infestation level in date palm gardens of Saudi Arabia. Planter. 76: 347-355.

Villatte, F., V. Marcel, S. Estrada-Mondac, and D. Fournier, 1998. Engineering sensitive acetylcholinesterase for detection of organophosphate and carbamate insecticides. Biosens. Bioelectron., 18: 34-39.

Weaver, D.K., F.V. Dunkel, L. Ntezurubanza, L.L. Jackson, and D.T. Stock, 1991. The efficacy of linalool, a major component of freshly-milled Ocimum canum Sims (Lamiaceae), for protection against postharvest damage by certain stored product Coleoptera. J. Stored Prod. Res., 27: 213220.

Wu, H., R. Zhang, J. Liu, Y. Guo, and E. Ma, 2011. Effects of malathion and chlorpyrifos on acetylcholinesterase and antioxidant defense system in Oxya chinensis (Thunberg) (Orthoptera: Acrididae). Chemosphere, 83: 599-604.

Yang, M., J. Zhang, K.Y. Zhu, T. Xuan, X. Liu, Y. Guo, and E. Ma, 2008. Increased activity and reduced sensitivity of acetylcholinesterase associated with malathion resistance in a field population of the oriental migratory locust, Locusta migratoria manilensis (Meyen). Pest. Bioch. Physiol., 91: 3238.

Yu, S.J., 2006. Insensitivity of acetylcholinesterase in a field strain of the fall army worm, Spodoptera frugiperda (J. E. Smith). Pestic. Biochem. Physiol., 84: 135-142.

Zibaee, A., 2011. Botanical insecticides and their effects on insect biochemistry and immunity. In "Pesticides in the modern world - Pests control and pesticides exposure and toxicity assessment" (Ed. M. Stoytcheva). Publisher: In Tech., 55-68. 